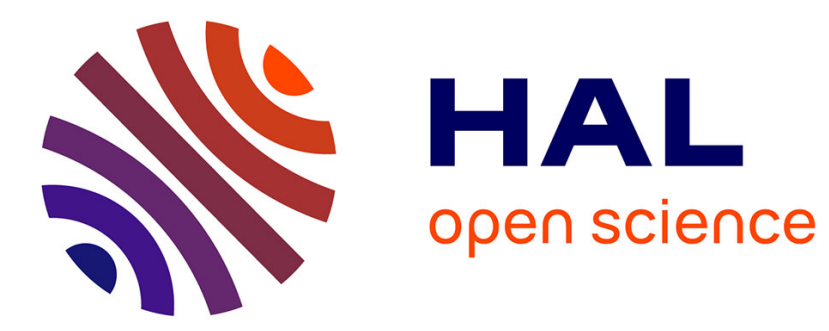

\title{
On the role of a Rossby wave train during the extratropical transition of hurricane Helene (2006)
}

Florian Pantillon, Jean-Pierre Chaboureau, Christine Lac, Patrick Mascart

\section{To cite this version:}

Florian Pantillon, Jean-Pierre Chaboureau, Christine Lac, Patrick Mascart. On the role of a Rossby wave train during the extratropical transition of hurricane Helene (2006). Quarterly Journal of the Royal Meteorological Society, 2013, 139 (671), pp.370-386. 10.1002/qj.1974 . hal-00923941

\section{HAL Id: hal-00923941 \\ https://hal.science/hal-00923941}

Submitted on 1 Feb 2022

HAL is a multi-disciplinary open access archive for the deposit and dissemination of scientific research documents, whether they are published or not. The documents may come from teaching and research institutions in France or abroad, or from public or private research centers.
L'archive ouverte pluridisciplinaire HAL, est destinée au dépôt et à la diffusion de documents scientifiques de niveau recherche, publiés ou non, émanant des établissements d'enseignement et de recherche français ou étrangers, des laboratoires publics ou privés.

\section{(ㄷ)(1) $\$$}

Distributed under a Creative Commons Attribution - NonCommercial| 4.0 International 


\title{
On the role of a Rossby wave train during the extratropical transition of hurricane Helene (2006)
}

\author{
F. Pantillon, ${ }^{\text {a }}$ J.-P. Chaboureau, ${ }^{\text {a C. }}$ Lac ${ }^{\mathrm{b}}$ and P. Mascart ${ }^{\mathrm{a}}$ \\ ${ }^{a}$ Laboratoire d'Aérologie, Université de Toulouse and CNRS, Toulouse, France \\ ${ }^{\mathrm{b}}$ CNRM-GAME, Météo-France and CNRS, Toulouse, France \\ ${ }^{*}$ Correspondence to: F. Pantillon, Laboratoire d’Aérologie, Observatoire Midi-Pyrénées, 14 avenue Edouard Belin, 31400 \\ Toulouse, France. E-mail: florian.pantillon@aero.obs-mip.fr
}

\begin{abstract}
Three successive interactions of hurricane Helene (2006) with a Rossby wave train during the extratropical transition of Helene over the North Atlantic were investigated. Numerical experiments were performed with different horizontal resolutions and configurations, over a domain that stretches from the eastern Pacific to the Western Mediterranean to encompass Helene and the whole Rossby wave train. In particular, a cloud-resolving run offered an explicit representation of strong diabatic effects involved in the three successive interactions.

While the circulation and moisture anomaly of Helene were essential to its own reintensification, it is shown that the Rossby wave train played an important role in the track and intensity of Helene and in explosive cyclogenesis downstream. First, the Rossby wave train steered Helene in such a way that a small difference in phasing resulted in large errors in the track of Helene. Only a run at kilometre scale was able to correctly forecast the 5-day track of Helene. Second, through the formation of three filaments, the Rossby wave train created a quasi-diurnal cycle in the intensity of Helene. Helene responded with strong diabatic activity that prevented the superposition of an upstream trough and enhanced a downstream ridge. Finally, model errors in the outflow of Helene propagated downstream with the group speed of the Rossby wave train, leading to the loss of predictability of a tropical-like cyclone over the Mediterranean. This study suggests that, in addition to the horizontal resolution, uncertainty from the model microphysics and from initial conditions need to be characterized to improve mid-range forecast downstream from an extratropical transition.
\end{abstract}

Key Words: extratropical transition; Rossby wave train; mesoscale modelling; horizontal resolution; diabatic processes; downstream predictability

1. Introduction

When moving into the mid latitudes, a tropical cyclone (TC) experiences a so-called extratropical transition (ET), which involves complex interactions of the TC with a preexisting mid-latitude baroclinic zone (for a review, see Jones et al., 2003). Klein et al. (2000) developed a conceptual model of ET in two stages. During the transformation stage, the TC weakens because of decreasing sea surface temperature and increasing vertical shear. The advection of dry air into the western quadrant of the TC and slantwise ascent in its eastern quadrant result in an asymmetric distribution of clouds and precipitation. The TC may then enter a reintensification stage by deepening as an extratropical cyclone. 
The presence of an upper-level trough often plays an important role during ET. The trough can impact both the reintensification and the track of the transitioning TC (Harr et al., 2000). For instance, McTaggart-Cowan et al. (2001) found that the deepening of hurricane Earl (1998) during its ET was driven by an upstream trough, while the characteristics of the TC played only a second role. In contrast, the rapid reintensification of Danielle (1998) required the presence of the TC circulation and moisture anomaly (McTaggart-Cowan et al., 2004). By displacing the TC in ET forecasts, Klein et al. (2002) showed that the phasing of the upper-level trough with the TC was critical for the reintensification. The phasing required the superposition of upper-level divergence, mid-level positive vorticity advection and low-level warm advection as in the classical Pettersen type-B conceptual model. A further demonstration was given by Ritchie and Elsberry (2007) with numerical experiments in which the distance between the TC and the trough was changed: the closer the TC was to the trough, the stronger was the reintensification.

The TC in turn impacts the upper-level mid-latitude circulation through diabatic processes that redistribute potential vorticity (PV) locally. Agusti-Panareda et al. (2004) illustrated that the outflow of the transitioning cyclone Irene (1999) modified an upper-level baroclinic wave over the North Atlantic. Strong diabatic heating maintained a broad negative PV anomaly at upper levels that delayed the interaction of the TC with an upstream trough and enhanced a downstream jet. This modification of the baroclinic wave propagated further downstream and triggered a surface cyclogenesis over the Bay of Biscay. These results were confirmed in idealized simulations, where the delayed interaction between the TC and the upper-level pattern promoted their phase-locking (Riemer et al., 2008). Recently, Grams et al. (2011) investigated several warm conveyor belts associated with the ET of Hanna (2008) and an upstream extratropical cyclogenesis over the North Atlantic. They showed the key role of diabatic processes in locally modifying the upper-tropospheric wave guide that subsequently triggered Mediterranean cyclogenesis a few days later.

Such downstream impact of TC during ET has been the focus of recent studies. Based on idealized simulations, Riemer and Jones (2010) showed how the cyclonic circulation and the divergent outflow of a TC amplified a ridge-trough couplet at upper levels. This amplification quickly propagated as a Rossby wave train and enhanced surface cyclogenesis downstream. In an alternative framework, Harr and Dea (2009) conducted local eddy kinetic energy analyses on four cases of ET over the western North Pacific. Downstream development was enhanced when the TC phased with an upstream trough. Harr et al. (2008) and Anwender et al. (2008) analysed ensemble forecasts over the western North Pacific and the North Atlantic. They found a systematic increase in the ensemble spread after ET events, confirmed by Keller et al. (2011) in a multimodel ensemble. Such an enhanced spread yielded different scenarios in the reintensification of the TC, associated with the amplitude and shift of an upper-level trough-ridge-trough pattern interacting with the TC. The ensemble spread propagated downstream with the group speed of a Rossby wave train and reduced the downstream predictability.

The role of a Rossby wave train during the ET of Helene (2006) over the North Atlantic is investigated here. Previous studies have underlined the importance of diabatic processes during this ET. In an early phase, Davis et al. (2008) found a strong diabatic response to quasi-geostrophic forcing that allowed strong ascents. The vertical mass flux increased proportionally to the vertical shear when Helene approached an upper-level trough. Lang et al. (2012) emphasized the role of moist processes on the downstream predictability during both the mature tropical phase and the ET of Helene. When taken into account for computing singular vectors in the vicinity of Helene, moist processes increased the downstream spread in ensemble forecasts. Chaboureau et al. (2012) further remarked the poor skill of deterministic forecasts for Europe during the ET of Helene. These forecasts missed the explosive downstream development of a surface cyclone into a tropical-like storm over Italy, described as a medicane (Mediterranean hurricane). No study has yet detailed the ET of Helene and its unusual triple interaction with a Rossby wave train.

The present study focuses on the diabatic effects involved in the ET. For this purpose, numerical experiments were performed for 5 days on a very large domain encompassing the Rossby wave train. They were aimed at describing both the interaction of the Rossby wave train with Helene and its downstream impact on the Mediterranean. In particular, a simulation was run at kilometre scale to examine the sensitivity of the ET to the explicit representation of cloud systems over the whole domain. The role of the Rossby wave train in the successive reintensifications was investigated, as was the influence of feedback from Helene on the upperlevel circulation. Attribution methods were applied in order to distinguish Helene from its ambient flow. They allowed us to explore the respective roles of the Rossby wave train and Helene during the ET. The downstream propagation of model uncertainties with the Rossby wave train was also examined, paying a particular attention to the rapid development of the medicane.

Section 2 gives an overview of the ET of Helene based on analyses and satellite observations. Section 3 presents the numerical experiments and the attribution methods. Results of the simulations for the evolution of Helene are given and assessed against satellite observation in section 4 . The role of the Rossby wave train on both the intensity and the track of Helene is examined in section 5. An analysis of the diabatic impact of Helene on the Rossby wave train and of the error propagation is carried out in section 6 . Section 7 concludes the paper.

\section{Overview of the ET of Helene}

Helene was a major hurricane of the North Atlantic 2006 season that developed from an African easterly wave on 11 September (Schwendike and Jones, 2010). It became a hurricane at 1200 UTC 16 September and reached its peak intensity at 0600 UTC 18 September with a surface wind speed of $105 \mathrm{kt}\left(54 \mathrm{~m} \mathrm{~s}^{-1}\right)$, attaining category 3 in the Saffir-Simpson scale. Helene then weakened until it started to recurve over the West Atlantic late on 21 September, and was officially declared extratropical at 1800 UTC 24 September (Franklin and Brown, 2008).

Figure 1 illustrates the evolution of Helene during and after its ET, with analyses from the European Centre for Medium-Range Weather Forecasts (ECMWF) and infrared (IR) satellite observations every $36 \mathrm{~h}$ (merged from all available geostationary satellites). At 0000 UTC 
(a)
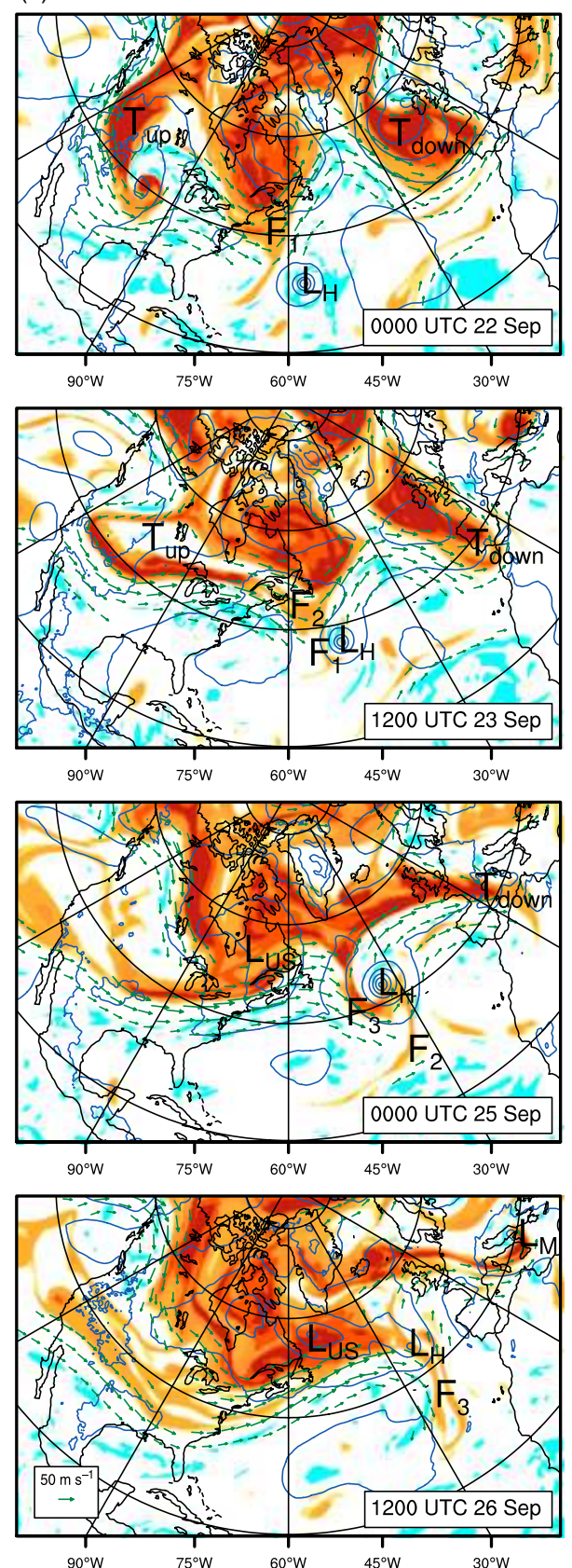

$250 \mathrm{hPa}$ potential vorticity (PVU)

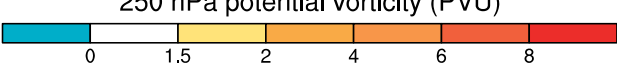

(b)
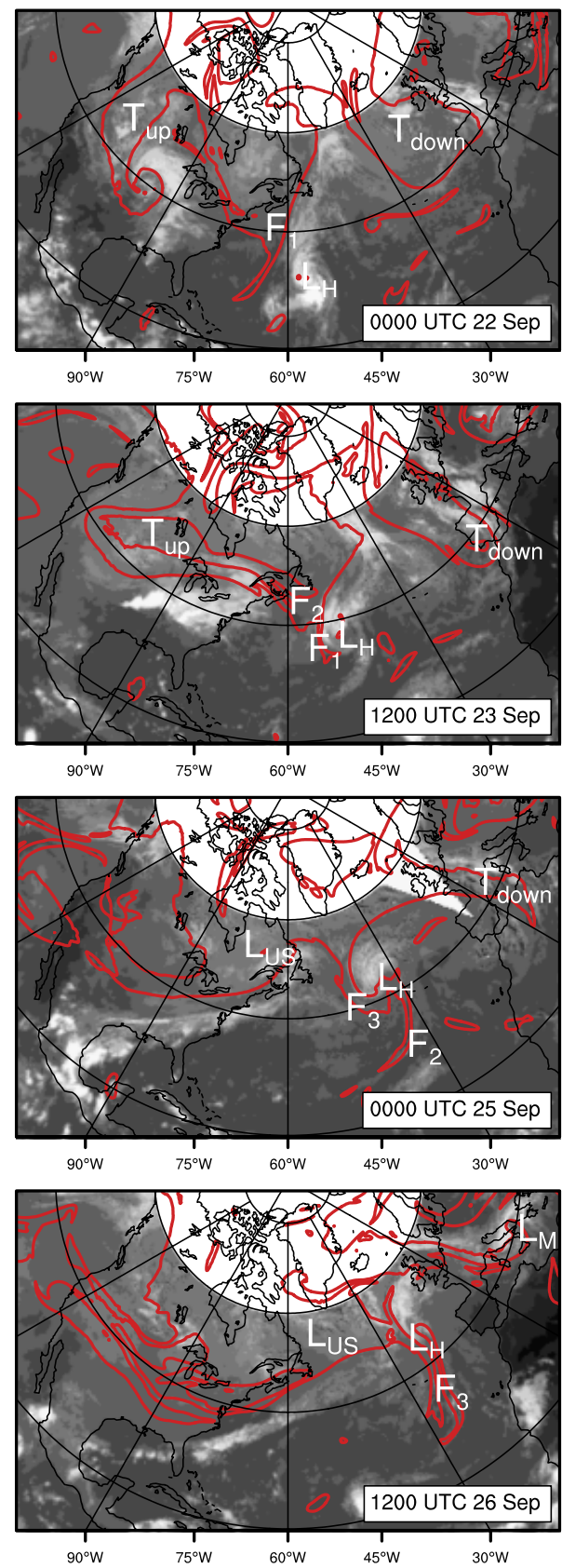

IR Brightness Temperature $(\mathrm{K})$

$\begin{array}{lllllllllll}220 & 230 & 240 & 250 & 260 & 270 & 280 & 290 & 300 & 310 & 320\end{array}$

Figure 1. (a) $250 \mathrm{hPa}$ potential vorticity (shading, $1 \mathrm{PVU}=10^{-6} \mathrm{~K} \mathrm{~m}^{2} \mathrm{~kg}^{-1} \mathrm{~s}^{-1}$ ), $250 \mathrm{hPa}$ wind (vectors over $30 \mathrm{~m} \mathrm{~s}{ }^{-1}$ ) and mean sea-level pressure (MSLP) (contours every $10 \mathrm{hPa}$ ) from the ECMWF analysis. (b) Globally merged IR brightness temperature (shading, K) and $250 \mathrm{hPa}$ potential vorticity (contour at 2 PVU). Labels mark the position of Helene $\left(\mathrm{L}_{\mathrm{H}}\right)$, the US low $\left(\mathrm{L}_{\mathrm{US}}\right)$, the Medicane $\left(\mathrm{L}_{\mathrm{M}}\right)$, upper-level troughs upstream $\left(\mathrm{T}_{\text {up }}\right)$ and downstream $\left(\mathrm{T}_{\text {down }}\right)$, and three PV filaments $\left(\mathrm{F}_{1}, \mathrm{~F}_{2}\right.$ and $\left.\mathrm{F}_{3}\right)$. This figure is available in colour online at wileyonlinelibrary.com/journal/qj

22 September, Helene $\left(\mathrm{L}_{\mathrm{H}}\right)$ was approaching an upper-level trough of a pronounced North Atlantic Rossby wave train (hereafter RWT) extending below $40^{\circ} \mathrm{N}$. A PV filament (hereafter $\mathrm{F}_{1}$ ) started elongating from this trough and soon interacted with Helene. The cloud pattern of Helene developed an asymmetry, revealed by a clear-sky area in the IR observation. An upper-level trough (hereafter $T_{\text {up }}$ ) upstream of RWT broke onto the central USA, creating a broad surface cyclogenesis.

At 1200 UTC 23 September, filament $F_{1}$ had wrapped cyclonically around Helene, and a second PV filament (hereafter $\mathrm{F}_{2}$ ) was elongating from the same upper-level trough as $\mathrm{F}_{1}$. Helene was located in the right-entrance region of a jet streak. Their phasing favoured the reintensification of Helene and enhanced the jet streak. The jet streak advected low-PV air from the outflow of Helene into the downstream ridge and the cloud pattern of Helene resembled a frontal system. The surface cyclone over the central USA had filled up and strong thunderstorms had developed along a remaining frontal line. At upper levels, remnants of the upstream trough $\mathrm{T}_{\text {up }}$ were joining filament $\mathrm{F}_{2}$, while a downstream trough (hereafter $\mathrm{T}_{\text {down }}$ ) of RWT was elongating towards the Iberian Peninsula, blocked on its eastern flank. 
At 0000 UTC 25 September, Helene reached a minimum in its surface pressure and ended its ET. A third PV filament (hereafter $\mathrm{F}_{3}$ ) was wrapping cyclonically around Helene, whereas the remnants of filament $\mathrm{F}_{2}$ had been advected southwards. The building of the downstream ridge was more evident and contributed to the further elongation of the downstream trough $\mathrm{T}_{\text {down }}$. The latter led to surface cyclogenesis over the Western Mediterranean Sea, as well as over the lee side of the Atlas Mountains. Meanwhile, a new cyclone (hereafter $\mathrm{L}_{U S}$ ) formed over the northeastern USA at the head of the thunderstorm line. It deepened over eastern Canada because of a baroclinic interaction with the upper level and built a new ridge upstream of Helene. Helene became secondary to $\mathrm{L}_{\mathrm{US}}$ and the associated ridge later contributed to the elongation of $\mathrm{F}_{3}$. Such a feature was also described by Grams et al. (2011) in the case of Hanna (2008).

At 1200 UTC 26 September, Helene was filling as an extratropical cyclone off the European coasts, while its cloud cover was dissipating. Its interaction with RWT was finished and filament $\mathrm{F}_{3}$ had been advected southwards. The US cyclone $\mathrm{L}_{U S}$ and its cloud cover were also dissipating over the Labrador Sea. The RWT had become more zonal over the western Atlantic. Increasing cyclonic activity was found over the Mediterranean only, where $\mathrm{T}_{\text {down }}$ had turned into a PV streamer and wrapped cyclonically around a surface low located over the Gulf of Genoa. Through an interaction with this PV streamer (Chaboureau et al., 2012), a smaller-scale surface low had developed into a medicane $\left(\mathrm{L}_{\mathrm{M}}\right)$.

A cyclone phase space diagram (Hart, 2003) depicts the structural evolution of Helene during its ET (Figure 2). Using the storm-motion-relative thickness and the thermal wind between 900 and $600 \mathrm{hPa}$, this diagram discriminates between a tropical symmetric warm-core cyclone and an extratropical asymmetric cold-core cyclone. It further encompasses hybrid cyclones like transitioning hurricanes and secluding extratropical lows.

Helene lost its tropical symmetry on 22 September, when the lower-tropospheric thickness asymmetry exceeded the standard threshold of $10 \mathrm{~m}$. Based on this diagnostic, 22 September was taken as the beginning of the ET of Helene. This day marked the beginning of interactions of Helene with the RWT and of the transformation of its cloud pattern. It was also when the size of Helene started to increase, as expected during an ET: its mean radius of gale-force winds grew from $428 \mathrm{~km}$ at 0000 UTC 22 September to $669 \mathrm{~km}$ at 0000 UTC 25 September. The maximum surface wind weakened as a consequence of this spatial extension of Helene.

From 0000 UTC 22 September onwards, the asymmetry of Helene slowly increased. Three steps were observed during the successive interactions of Helene with the three PV filaments $F_{1}, F_{2}$ and $F_{3}$, until the asymmetry vanished suddenly after 0000 UTC 25 September. Helene maintained a warm core during these 3 days, not only at low levels (Figure 2) but through the whole troposphere (not shown). These tropical characteristics of low asymmetry and deep warm core are not typical for an ET (Hart, 2003). A persistent warm core has been noted in other cases of ET. McTaggart-Cowan et al. (2003) distinguished the baroclinic reintensification of Earl (1998) from the tropical reintensification of Danielle (1998). Both developed a warm core during ET, Earl from a warm seclusion and Danielle from its tropical environment. Additional cyclone

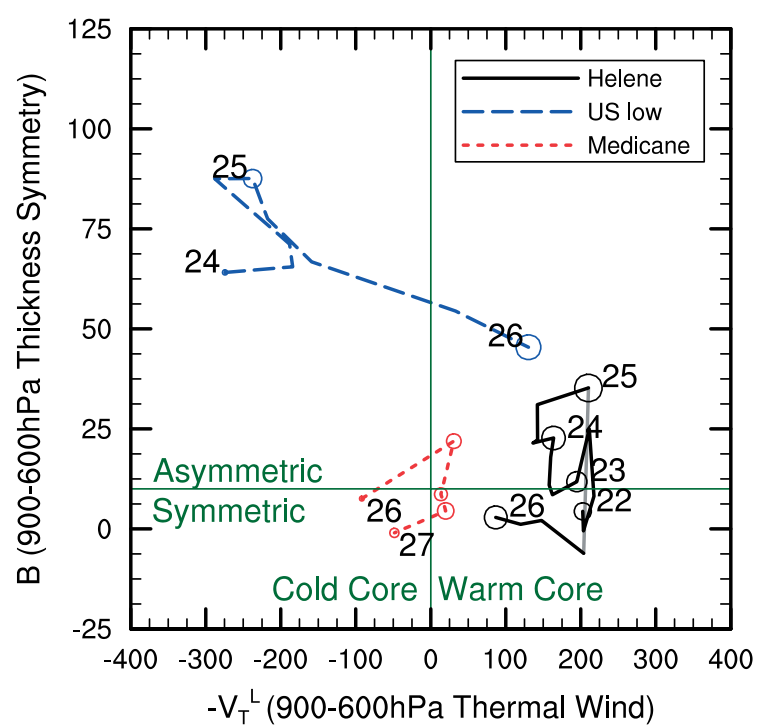

Figure 2. Cyclone phase space diagram from 6-hourly ECMWF analyses for Helene, the US low and the Medicane. Days are given at 0000 UTC in September 2006. The radii of circles are proportional to the mean radii of gale-force winds at $925 \mathrm{hPa}$. This figure is available in colour online at wileyonlinelibrary.com/journal/qj

phase space diagrams reveal that Helene differs from these two cases in the sense that it maintained a deep warm core during ET, whereas Earl and Danielle developed a shallow warm core after a cold-core phase (available at http://moe.met.fsu.edu/cyclonephase/). Helene occluded after 0000 UTC 25 September without turning into an asymmetric cold-core cyclone, unlike the conceptual model of Klein et al. (2000).

The structural evolution of two other cyclones is also depicted in Figure 2. The US low L $\mathrm{L}_{U}$ developed from a tiny surface anomaly on 24 September, then strengthened with increasing asymmetry and cold core until 25 September. Its spatial extent continued to grow during its mature stage and it acquired a shallow warm core revealing a warm seclusion over the Labrador Sea on 26 September. Over the Mediterranean Sea, a smaller cyclone $\mathrm{L}_{\mathrm{M}}$ developed on 26 September. The computation of its cyclone phase space parameters required a radius of $200 \mathrm{~km}$, instead of the standard $500 \mathrm{~km}$ used for Helene and the US low as recommended by Hart (2003). The initial weak perturbation at 0000 UTC first acquired an asymmetric structure and a shallow warm core but then turned into a symmetric cyclone with a moderate warm core. It briefly resembled a tropical cyclone at 1200 and 1800 UTC and was therefore described as a medicane.

\section{Model and methods}

\subsection{Model description and experimental design}

Meso-NH (Lafore et al., 1998) is a research model that can simulate atmospheric motions ranging from the synoptic scale to large-eddy simulations. It is based on the anelastic approximation of the pseudo-incompressible system of Durran (1989). This grid-point Eulerian model uses a fourth-order centred advection scheme for the momentum components and the piecewise parabolic method (PPM) advection scheme for other variables (Colella and Woodward, 1984). The temporal scheme 
is hybrid. It uses forward time differencing for the thermodynamic variables and leap-frog differencing for the velocity components.

In this study, Meso-NH version 4.8 was run on a domain that stretches from the eastern Pacific to the Western Mediterranean, shown in Figure 1. Such a large domain allowed a description of the mid-range evolution of the RWT that did not rely on boundary conditions, as confirmed with a sensitivity test mentioned below. A regional run with a $24 \mathrm{~km}$ grid mesh (hereafter LowRes) was compared with a cloud-resolving run with a $4 \mathrm{~km}$ grid mesh (hereafter HiRes). The LowRes run had a resolution similar to that of the deterministic ECMWF forecast with a T799 truncation. Both Meso-NH runs used a Kain-Fritsch-Bechtold parametrization scheme for the subgrid deep convection (Bechtold et al., 2001) and an eddy diffusive Kain-Fritsch parametrization scheme for the subgrid shallow convection (Pergaud et al., 2009). They further included a subgrid cloud scheme (Chaboureau and Bechtold, 2005), a microphysical scheme for mixed-phase clouds (Pinty and Jabouille, 1998), and parametrizations for the turbulence (Cuxart et al., 2000) and air-sea fluxes (Belamari, 2005).

We expected HiRes to explicitly describe the strong diabatic processes that occurred during the ET of Helene. To test this assumption, a sensitivity run was performed with the same grid as HiRes but with the deep convection scheme turned off. No significant impact was found either on the precipitation pattern or on the dynamics of Helene, showing the capability of HiRes to resolve strong ascents. As some smaller-scale convective features were simulated when using the deep convection scheme only, HiRes was preferred to the sensitivity run.

The model was initialized from the ECMWF analysis at 0000 UTC 22 September and run for 5 days using 6-hourly ECMWF analyses as lateral boundaries. A sensitivity run did not show any significant impact on the ET of Helene when ECMWF forecasts were employed as lateral boundaries. This suggests that the RWT developed within the model domain and was independent of the lateral boundaries. Model fields were interpolated on a polar stereographic grid and 70 vertical levels. This interpolation resulted in a $512 \times 320$ horizontal grid for the LowRes run and in a $3072 \times 1920$ horizontal grid for the HiRes run.

The HiRes run was made possible by recent developments of the Meso-NH model for large grids (Pantillon et al., 2011). A new parallelization of the pressure solver allowed efficient computing on 4096 cores of an SGI ICE cluster. A 5-day run with a $5 \mathrm{~s}$ time step required half a million computing hours. Input and output fields were written level by level to limit the file size. They were averaged on the LowRes $24 \mathrm{~km}$ grid for post-processing.

\subsection{Attribution methods}

Attribution methods are powerful tools to isolate individual features from the ambient flow and investigate their roles in complex interactions. In the context of ET, they allow the mutual impact of the TC and its environment to be understood. Several authors have used a piecewise PV inversion for this purpose (McTaggartCowan et al., 2001; Agusti-Panareda et al., 2004; Riemer et al., 2008; Grams et al., 2011; among others). Because no PV inversion tool was available to us, two alternative methods were used to isolate Helene from its environment: an attribution of vorticity was performed to evaluate the steering of Helene by its environmental flow at a given time and Helene was filtered out from the initial ECMWF analysis to evaluate its impact on the downstream development.

The attribution of vorticity was based on a Helmholtz partitioning to obtain the stream function from a selected vorticity field. The vorticity was first averaged vertically between 950 and $250 \mathrm{hPa}$ every $50 \mathrm{hPa}$ to apply this two-dimensional method to the whole free troposphere. The resulting vorticity was attributed to Helene within a $250 \mathrm{~km}$ radius from its maximum, while the vorticity outside this radius was attributed to the environment. A Poisson equation for the stream function was then solved by over-relaxation on a $2000 \times 2000 \mathrm{~km}$ subdomain with appropriate lateral boundary conditions. For the cyclonic part, the Poisson equation was solved with a vanishing stream function at the lateral boundaries while, for the environmental part, the stream function at the lateral boundaries was computed from the total wind. In the second case, the stream function obtained by solving the Poisson equation included both the rotational and harmonic components of the wind. The latter, non-rotational and nondivergent, component appears when Helmholtz partitioning is applied to a limited area (Lynch, 1989). The vertically averaged divergent component was not considered. Its rather small value could not be easily attributed to Helene or to its environment.

The filtering of Helene was performed in four steps, following the approach of Kurihara et al. (1993) as in Klein et al. (2002), implemented in Meso-NH by Nuissier et al. (2005). Firstly, a low-pass Barnes filter with a 1500 $\mathrm{km}$ half-width was applied to fields of wind, potential temperature and specific humidity at each vertical level. The filter isolated the environmental part, which was subtracted from the total fields. Secondly, the circulation centre was defined as the grid point of minimum wind speed at the boundary layer top around $900 \mathrm{hPa}$. This dynamical centre matched the surface pressure minimum to within one grid point. Thirdly, the cyclone radius $\mathrm{R}_{0}$ was defined again at the top of the boundary layer with a threshold on the tangential wind. This radius $\mathrm{R}_{0}$ was computed separately in $10^{\circ}$ azimuthal bins to take the asymmetry of Helene into account. Finally, a cylindrical filter was applied in each azimuthal bin to extract the cyclonic part, which was again subtracted from each of the three meteorological fields. This last filter was a smooth function defined such that the cyclonic part vanished in $\mathrm{R}_{0}$ and the remaining part took a mean environmental value in the cyclone centre.

\section{Evolution of Helene in simulations}

\subsection{Track and intensity of Helene}

In the ECMWF analysis, Helene turned eastward on 22 September and left the warm sector of the Atlantic Ocean for a sea surface temperature below $26^{\circ} \mathrm{C}$ (Figure 3 ). It reintensified with three successive deepenings in 3 days, attaining a minimum of mean sea-level pressure (MSLP) of $958 \mathrm{hPa}$ at 0000 UTC 25 September (Figure 4). This quasi-regular oscillation of the surface pressure matched the 


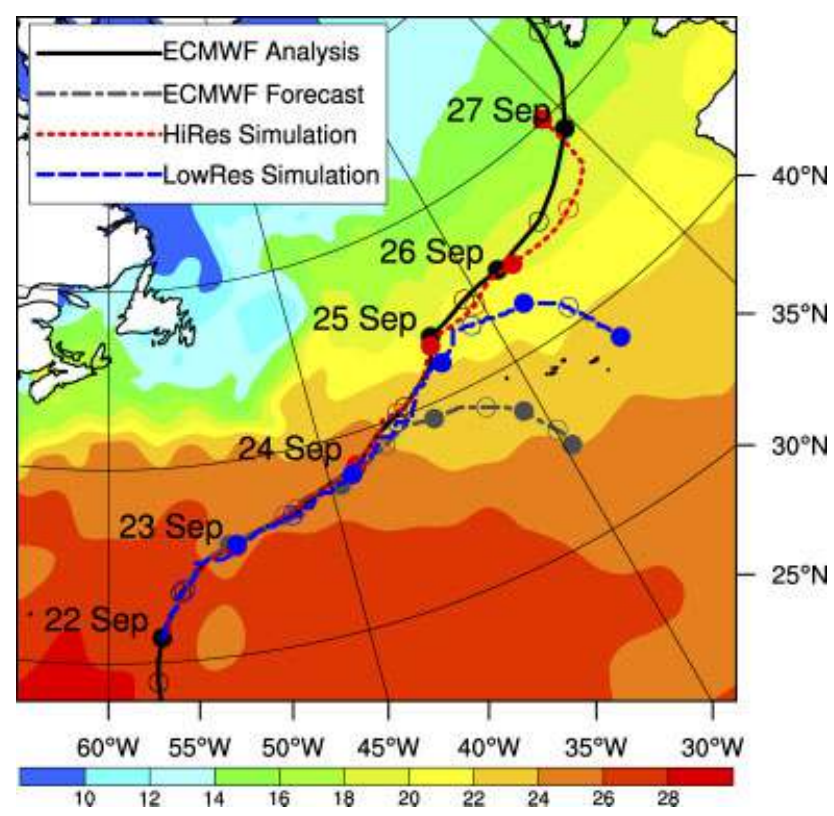

Figure 3. Sea surface temperature at 0000 UTC 22 September 2006 from the ECMWF analysis (shading in ${ }^{\circ} \mathrm{C}$ ) and track of Helene in the ECMWF analysis and operational forecast, and in Meso-NH HiRes and LowRes runs. Filled circles at 0000 UTC and hollow circles at 1200 UTC. This figure is available in colour online at wileyonlinelibrary.com/journal/qj

wrap-up of the three filaments $\mathrm{F}_{1}, \mathrm{~F}_{2}$ and $\mathrm{F}_{3}$. Helene then occluded over the eastern Atlantic and filled quickly.

The Meso-NH runs differed in the track of Helene (Figure 3). The hurricane followed the analysed track closely in both HiRes and LowRes during its ET from 22 to 25 September. Afterwards, the track of the ex hurricane was correctly forecast towards the British Isles in HiRes. In contrast, it wrongly turned southeastwards in LowRes, as it did 1 day earlier in the deterministic ECMWF forecast. This bifurcation of tracks is explained in section 5.4.

Both HiRes and LowRes simulated the three deepenings in 3 days during the ET of Helene followed by the quick filling (Figure 4). LowRes matched the MSLP minimum of the ECMWF analyses, whereas HiRes showed a deeper hurricane, closer to the operational forecast. This deeper surface pressure at higher resolution was also observed when forecasting the tropical phase of mature cyclones with the Weather Research and Forecasting Model (Davis et al., 2010). A final deepening of Helene was simulated in HiRes late on 26 September when Helene merged with an other low. This merging was missed in LowRes because of the incorrect track computed for Helene.

Figure 5 further concentrates on the reintensification of Helene in LowRes and HiRes. The precipitation rate emphasizes the quasi-regular oscillation of the cyclone intensity already seen in the MSLP minimum. Three bursts of precipitation occurred in 3 days, with minima in the morning and maxima in the evening. The origin of such a diurnal cycle is investigated in section 5.2.

HiRes and LowRes produced very similar amounts of $24 \mathrm{~h}$ accumulated precipitation, within a few percent during the first two intensifications (Table 1). A difference arose during the third intensification, with LowRes producing about $20 \%$ more precipitation than HiRes and with a maximum delayed by $6 \mathrm{~h}$. This difference is explained in section 5.3 . The vanishing precipitation rates after 25 September were not significantly impacted by the divergence of tracks.
22 Sep 23 Sep 24 Sep 25 Sep 26 Sep 27 Sep

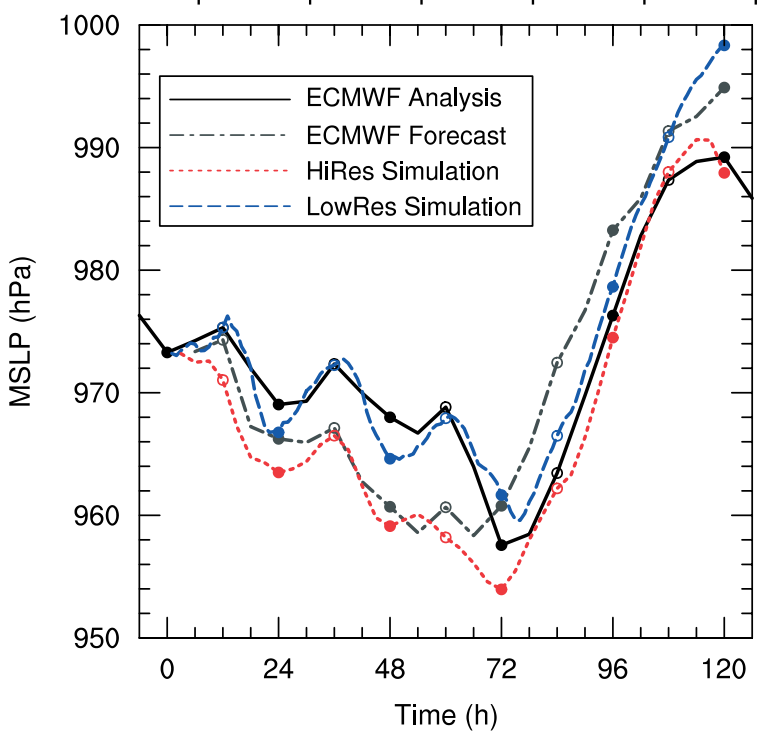

Figure 4. Temporal evolution of the MSLP minimum of Helene from 0000 UTC 22 September 2006, in the ECMWF analysis and operational forecast, and in Meso-NH HiRes and LowRes runs. Filled circles at 0000 UTC and hollow circles at 1200 UTC. This figure is available in colour online at wileyonlinelibrary.com/journal/qj

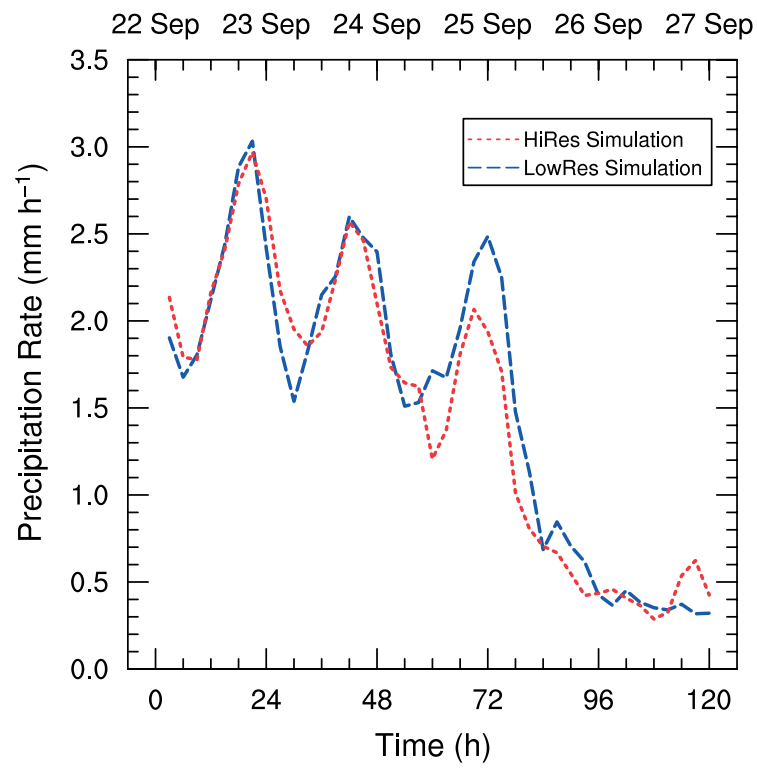

Figure 5. Temporal evolution of the precipitation rate from 0000 UTC 22 September 2006 averaged in a $400 \mathrm{~km}$ radius around the MSLP minimum of Helene, in Meso-NH HiRes and LowRes runs. This figure is available in colour online at wileyonlinelibrary.com/journal/qj

\subsection{Assessment against satellite observation}

The precipitation and cloud distributions in HiRes and LowRes were compared to satellite observations at the beginning of the second intensification. Observations from the Advanced Microwave Sounding Unit, instrument B (AMSU-B) with a $16 \mathrm{~km}$ resolution at nadir, were used at 1400 UTC 23 September. To assess the diabatic effects at lower levels, the precipitation rate was retrieved from the satellite observations using the algorithm of Laviola and Levizzani (2011). The retrieved precipitation rate allowed a direct comparison with the model fields. At higher levels, the upper tropospheric humidity was computed from 
Table 1. $24 \mathrm{~h}$ accumulated precipitation starting and ending at 0600 UTC in September 2006, averaged in a $400 \mathrm{~km}$ radius around the MSLP minimum of Helene, in Meso-NH HiRes and LowRes runs.

\begin{tabular}{llc}
\hline Time & HiRes & LowRes \\
\hline $22-23$ Sep. & $57 \mathrm{~mm}$ & $54 \mathrm{~mm}$ \\
$23-24$ Sep. & $50 \mathrm{~mm}$ & $51 \mathrm{~mm}$ \\
$24-25$ Sep. & $38 \mathrm{~mm}$ & $46 \mathrm{~mm}$ \\
\hline
\end{tabular}

model fields and from the satellite observations using the retrieval algorithm of Buehler and John (2005). In this case, a comparison first required the microwave brightness temperature to be simulated from the model fields (see Chaboureau et al., 2008, and references therein).

On the microwave observation, a first area of precipitation lay close to the cyclone centre and a remote line extended to the northeast (Figure 6(a)). The former looked like a remnant band of tropical deep convection, while the latter had the characteristics of an extratropical warm front. The frontal precipitation was created by the strong lowlevel cyclonic circulation, which advected tropical air into a pre-existing baroclinic zone. Both HiRes and LowRes produced intense precipitation close to the cyclone centre, with much higher precipitation rates than in the observation (Figure $6(b, c))$. Further north, both runs produced intense precipitation in the southwestern part of the warm front as observed but they missed its northeastern extension. This lack of precipitation suggests a dry bias of the model in this area and thus an underestimation of the diabatic heating.

Both runs also produced rain in the tropical sector east of Helene and along a weak cold front south of Helene. This precipitation was barely observed because of the low sensitivity of the algorithm, which is based on the scattering of the microwave signal by large precipitating hydrometeors only. The gridded pattern of precipitation in LowRes is typical of the deep convection scheme. The latter was also active in HiRes but the resulting precipitation pattern was smoothed by the interpolation from a $4 \mathrm{~km}$ to a $24 \mathrm{~km}$ grid. Apart from this difference in the tropical sector and along the weak cold front, both spatial distribution and intensity of precipitation were similar in HiRes and LowRes, confirming their mesoscale forcing. Furthermore, most of the intense precipitation north of Helene was explicitly produced by the microphysical scheme, both in HiRes and in LowRes. We therefore considered that the LowRes run represented Helene well enough and used it as a reference for sensitivity runs.

For upper levels, the upper-tropospheric humidity and the wind field at $250 \mathrm{hPa}$ are shown in Figure 6(d-f). The microwave observation exhibits a large area of clouds, the production of which by core convection and frontal ascent is indistinguishable. The wind field in the ECMWF analysis reveals that Helene was located in the right entrance of a downstream jet streak that favoured upward motion. The outflow of Helene in turn strengthened the jet, which advected the clouds towards the downstream ridge. In the southwestern quadrant of Helene, a dry intrusion related to the filament $F_{1}$ can be seen on the microwave observation. The dry air wrapped cyclonically around Helene and contributed to the erosion of its core convection. Clouds are also visible along the weak cold front south of Helene and give credibility to the presence of precipitation simulated by the deep convection scheme in this area.

Both HiRes and LowRes (Figure 6(e,f)) simulated the large area of clouds and its advection by the jet streak, the dry intrusion in the southwest, and clouds in the tropical sector. Though an overall wet bias, these simulated features compare well with the observations and give greater confidence in the skill of the Meso-NH runs to represent Helene. Like the precipitation pattern, the upper-tropospheric humidity in both HiRes and LowRes has a similar distribution but differs in intensity in comparison with the microwave observation. A saturation in the retrieval algorithm could explain this difference.

\section{Impact of the Rossby wave train on Helene}

Helene reintensified three times during ET with a quasiregular oscillation in its MSLP and precipitation rate (Figures 4 and 5). The representation of Helene during its second intensification was similar in the two runs (Figure 6), though with a deeper surface pressure in HiRes than in LowRes (Figure 4). A divergence grew later with more precipitation in LowRes than in HiRes during the third intensification (Figure 5). After ET, a clear difference between HiRes and LowRes appeared in the track of Helene (Figure 3). The role of the RWT in the reintensifications and in the bifurcation of tracks is now examined.

\subsection{Strong diabatic response to a large-scale uplift}

To better understand the precipitation distribution of Helene, the $\omega$ equation was solved from model fields of LowRes. The vertical velocity $\omega$ was obtained from both dynamical and diabatic forcings, using the Q-vector formulation with an alternative balance and in the $f$-plane approximation (Mallet et al., 1999). The $\omega$ equation was solved by over-relaxation from model fields interpolated every $50 \mathrm{hPa}$ in the vertical, with $\omega$ vanishing at the lateral boundaries of a $600 \times 600 \mathrm{~km}$ subdomain and at the vertical boundaries at 1000 and $100 \mathrm{hPa}$. The diabatic heating was computed from the microphysical and deep convection schemes during the model run.

Figure 7 focuses again on the second intensification of Helene during its maximum precipitation at 1800 UTC 23 September $(t+42)$. The area of upward motion corresponds to the precipitation area shown $6 \mathrm{~h}$ earlier in Figure 6(c). Areas of frontal ascent and of core convection have merged and are wrapping cyclonically around Helene, following the low-level baroclinic zone and filament $\mathrm{F}_{2}$ (Figure $7(\mathrm{a})$ ). A vertical cross-section shows a dipole of vertical velocity along slanted moist isentropes over the warm front to the northnorthwest of Helene (Figure 7(c)) as in the conceptual model of the transformation stage of Klein et al. (2000). The area of slantwise convection has merged with a plume of deep convection closer to the core of Helene. Both types of convection diabatically maintain the PV tower of Helene with its associated warm core and cyclonic circulation.

Vertical velocities from the $\omega$ equation (Figure 7(b)) match both the structure and intensity of the vertical velocities from the model. Only the downward motions are overestimated. The dynamical forcing alone produced a weak, smooth ascent north and west of Helene. Moist air 
(a) AMSU-B and ECMWF

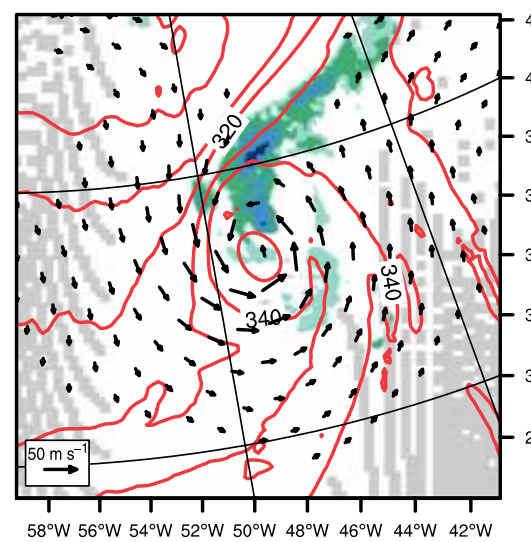

$58^{\circ} \mathrm{W} 56^{\circ} \mathrm{W} 54^{\circ} \mathrm{W} 52^{\circ} \mathrm{W} 50^{\circ} \mathrm{W} 48^{\circ} \mathrm{W} 46^{\circ} \mathrm{W} 44^{\circ} \mathrm{W} 42^{\circ} \mathrm{W}$ (b) HiRes

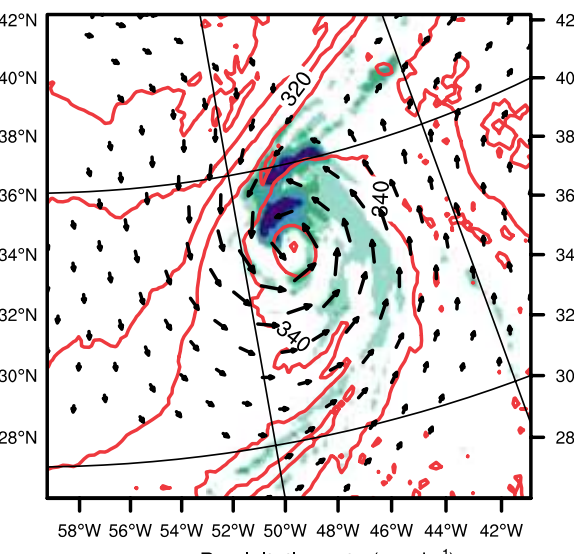

Precipitation rate $\left(\mathrm{mm} \mathrm{h}^{-1}\right)$ (c) LowRes

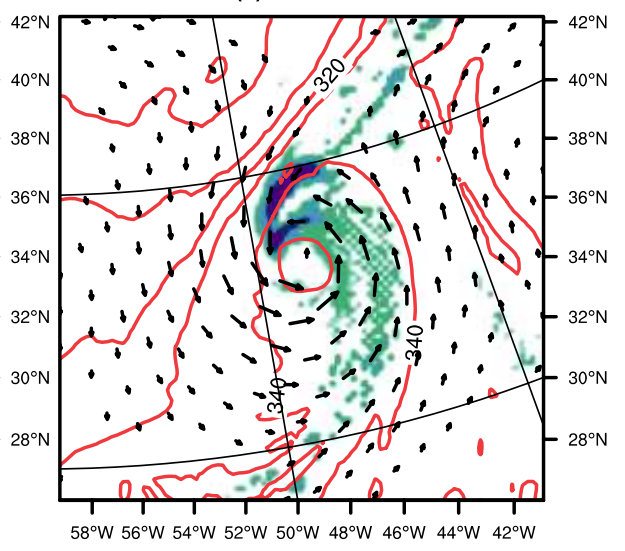

(d) AMSU-B and ECMWF

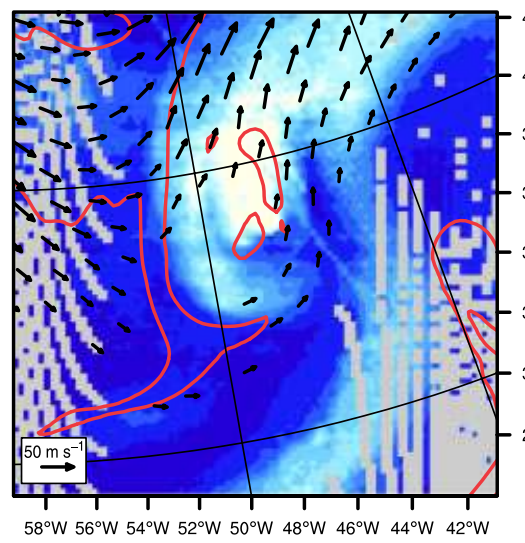

(e) HiRes

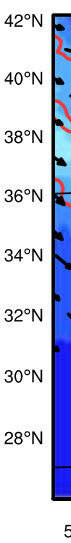

15 (f) LowRes

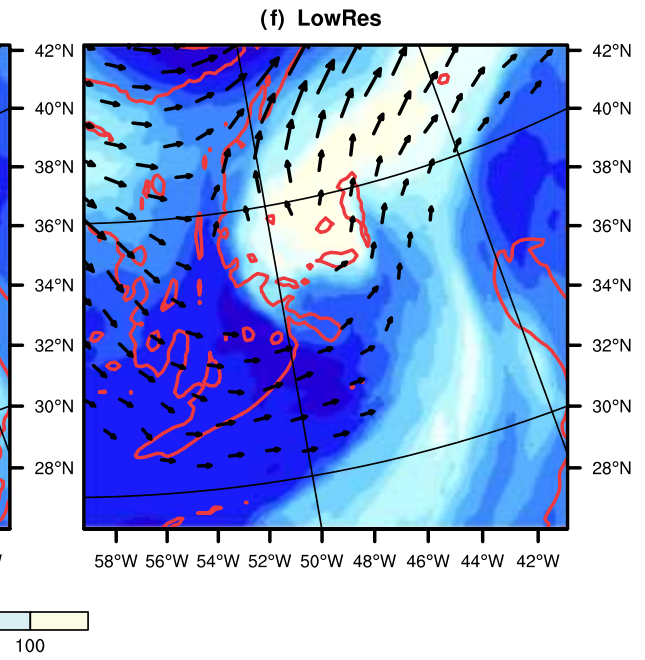

Figure 6. (a-c) Precipitation rate (shading, $\mathrm{mm} \mathrm{h}^{-1}$ ), $925 \mathrm{hPa} \theta_{E}$ (contours every $10 \mathrm{~K}$ ) and $925 \mathrm{hPa}$ wind (vectors above $10 \mathrm{~m} \mathrm{~s}{ }^{-1}$ ). (d-f) Upper tropospheric humidity (shading, $\%$ ), $250 \mathrm{hPa}$ potential vorticity (contours at $1.5 \mathrm{PVU}$ ) and $250 \mathrm{hPa}$ wind (vectors above $30 \mathrm{~m} \mathrm{~s} \mathrm{~s}^{-1}$ ). Fields on 23 September 2006 from (a, d) AMSU-B observation at 1400 UTC and ECMWF analysis at 1200 UTC, (b, e) Meso-NH HiRes and (c, f) Meso-NH LowRes runs at $1200 \mathrm{UTC}(t+36)$. All fields are interpolated on the same $24 \mathrm{~km}$ grid. This figure is available in colour online at wileyonlinelibrary.com/journal/qj

condensed in response to this large-scale uplift and released latent heat to create strong ascents. The resulting diabatic forcing dominated the dynamical forcing by an order of magnitude. This result shows the role of moist processes in explaining the intensification of Helene during its ET.

The dynamical forcing also played an important role in favouring the ascents at both low and high levels (Figure 7(b, d)). In the Q-vector formulation, the dynamical forcing is caused by both the temperature advection and the differential vorticity advection. The low-level part was certainly related to warm advection and created the dipole of vertical velocity to the northnorthwest of Helene. The upper-level part created another dipole of vertical velocity centred on Helene, but with an unclear origin as the PV filament remained too far away to advect vorticity in this region. Instead, the dynamical upper-level forcing might be explained through the differential advection of the PV tower of Helene itself. The origin of the upper-level forcing remains an aspect for future research. Note that strong vertical motions in the tropical air southeast of Helene were too small to be resolved by the dynamical forcing. They were found in the diabatical forcing only through the heating term from the deep convection scheme.

\subsection{Origin of three reintensifications of Helene}

The time evolution of the precipitation pattern during the ET of Helene is now studied along with its relationship with three PV filaments at upper levels. A time-azimuth plot shows this evolution in cyclone-following polar coordinates for LowRes and HiRes (Figure 8). The precipitation was mainly located along the warm front north of Helene. Early rain bands to the east of Helene, prior to the interaction with the baroclinic zone, vanished during the first day of simulation.

Three peaks of precipitation occurred north of Helene around 1800 UTC 22 September $(t+18), 1800$ UTC 23 September $(t+42)$ and 0000 UTC 25 September $(t+72)$. All three were preceded by the approach of a PV filament $\left(F_{1}, F_{2}\right.$ and $F_{3}$, respectively), which apparently enhanced the precipitation. Accordingly, the filament $\mathrm{F}_{3}$ was deeper in LowRes than in HiRes and was followed by a stronger precipitation peak. This suggests that the occurrence of three successive intensifications of Helene originated from the dynamics of the RWT and not from internal forcing proper to Helene.

After each peak, the burst of precipitation wrapped cyclonically around Helene (dashed lines in Figure 8). It 
(a) vertical velocity from model

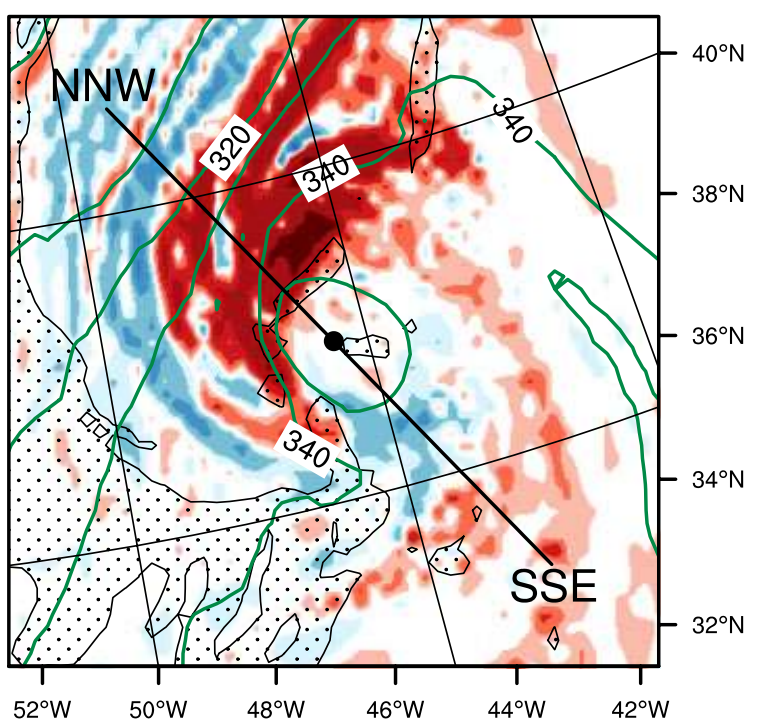

(c) vertical velocity from model

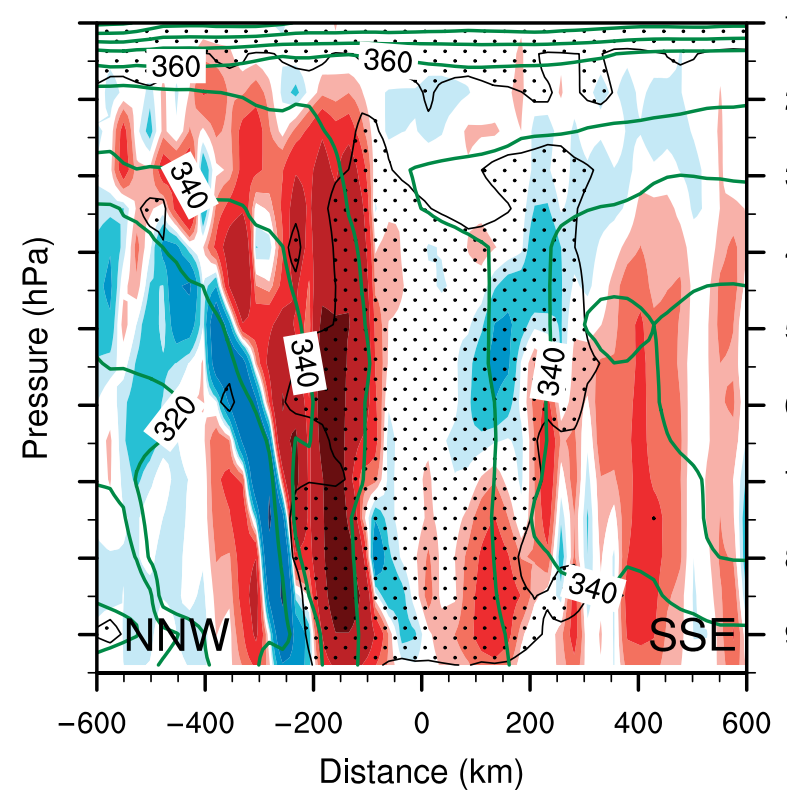

(b) vertical velocity from forcings

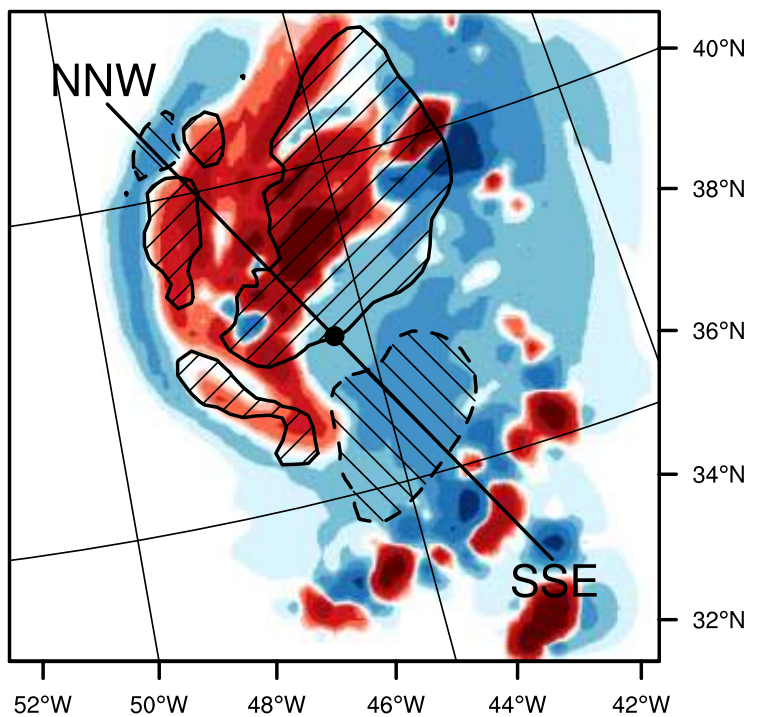

(d) vertical velocity from forcings

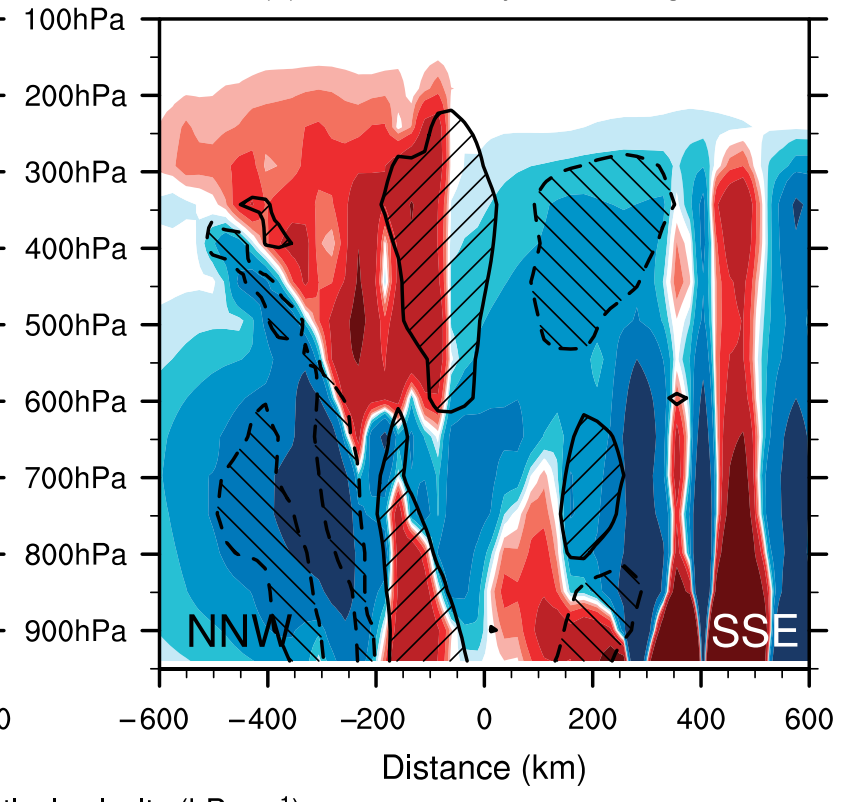

Vertical velocity $\left(\mathrm{hPa} \mathrm{s}^{-1}\right)$

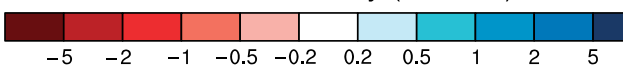

Figure 7. Vertical velocity $\omega$ (shading, $\mathrm{hPa} \mathrm{s}^{-1}$ ) in the LowRes run at 1800 UTC 23 September $2006(t+42)$ : (a) from model fields at 400 hPa, with 250 $\mathrm{hPa}$ potential vorticity (dotted surface at $1.5 \mathrm{PVU}$ ) and $950 \mathrm{hPa} \theta_{E}$ (contours every $10 \mathrm{~K}$ ); (b) from dynamical and diabatic forcings at $400 \mathrm{hPa}$ and from the dynamical forcing only (hashed surfaces over $\left|0.2 \mathrm{hPa} \mathrm{s}^{-1}\right|$, upward motion with solid line and downward motion with dashed line). Fields in (c) and (d) as in (a) and (b) but in northnorthwest to southsoutheast vertical cross-sections centred on the MSLP minimum of Helene; see trace on (a) and (b). This figure is available in colour online at wileyonlinelibrary.com/journal/qj

was advected by the cyclonic circulation of Helene with a revolution time of about $18 \mathrm{~h}$. This evolution was also observed in microwave satellite observations, despite their lack of temporal continuity (not shown). The three PV filaments also wrapped around Helene, but at a slower rate because of a slower cyclonic circulation at upper levels. The filaments $F_{1}$ and $F_{2}$ followed each other, in a similar way in LowRes and HiRes. In contrast, $\mathrm{F}_{3}$ was clearly separated from the first two filaments and appeared much more compact in LowRes than in HiRes. This difference between the runs is discussed below in the impact of the model resolution.

Davis etal. (2008) observed two revolutions of the precipitation pattern of Helene from 20 to 23 September, during the preliminary phase of its ET. They suggested an indirect impact of an approaching upper-level trough. Using the quasi-geostrophic framework, they showed that an increasing environmental vertical shear induced a tilt of the hurricane PV tower, which started to precess cyclonically around a stable left-of-shear position. They further found a quasi-geostrophic forced ascent in the downtilt direction, moving towards the cyclone centre during precessions.

With a cyclone tilt defined as the difference of the PV centre of mass between two levels as in Davis et al. (2008), two complete revolutions of the cyclone tilt were found during the first and third intensifications of Helene. These revolutions were followed by those of the precipitation 
(a) HiRes

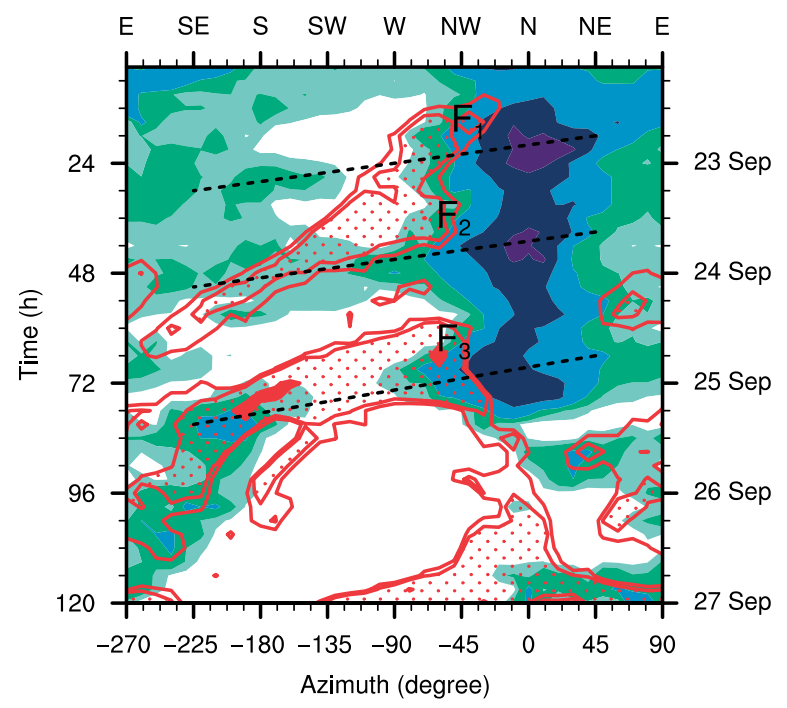

(b) LowRes

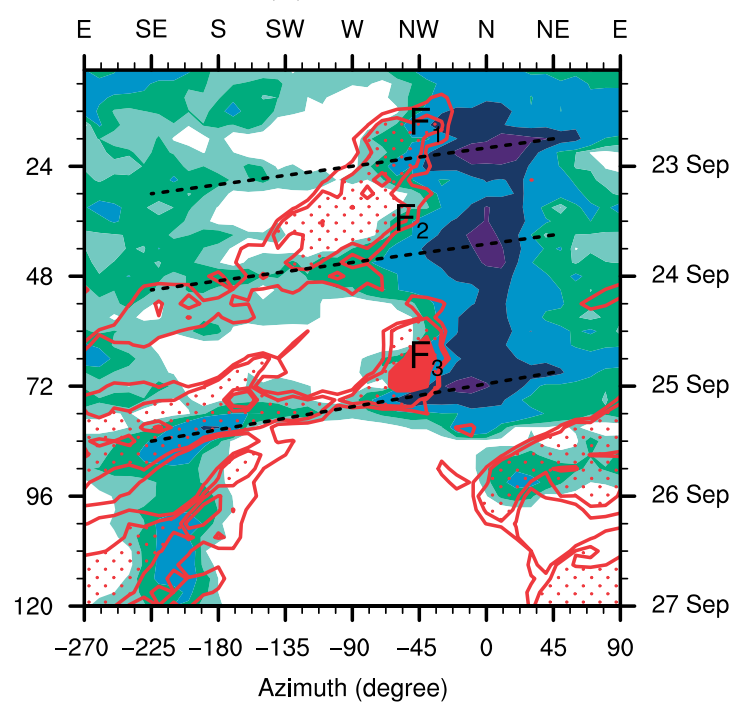

Precipitation rate $\left(\mathrm{mm} \mathrm{h}^{-1}\right)$

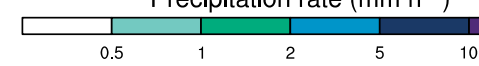

Figure 8. Time-azimuth plot in MesoNH (a) HiRes and (b) LowRes runs. Temporal evolution from 0000 UTC 22 September 2006 of the precipitation rate within a $400 \mathrm{~km}$ radius around Helene (shaded, $\mathrm{mm} \mathrm{h}^{-1}$ ) and of the $250 \mathrm{hPa}$ potential vorticity in a $300-600 \mathrm{~km}$ annulus around Helene (contour at 1.5 PVU, dotted surface at 2 PVU and filled surface at 5 PVU). Fields are averaged in $10^{\circ}$ azimuthal bins centred on the MSLP minimum of Helene. Labels mark the position of the three PV filaments $\left(\mathrm{F}_{1}, \mathrm{~F}_{2}\right.$ and $\left.\mathrm{F}_{3}\right)$ and dashed lines follow the wrap-up of the precipitation. This figure is available in colour online at wileyonlinelibrary.com/journal/qj

pattern. During the second intensification, though, the tilt was too weak to be given a clear direction. This weaker tilt was attributed to a more remote PV filament than during the first and third intensifications and to a weaker induced vertical shear.

Even though it was not found in the cyclone tilt, a revolution of the precipitation pattern also occurred during the second intensification of Helene. Further considering that the outward-moving precipitation in our simulations was opposed to the inward-moving pattern in Davis et al. (2008), the precession of Helene cannot be responsible for the simulated revolution of precipitation. Here, the computed tilt and rotation of the PV tower would rather be an artefact of the intrusion of PV from the filaments, limited during the second intensification.

Alternatively, the diurnal intensifications of Helene might originate from its own internal dynamics. Diurnal cycles in the intensity of tropical cyclones are observed statistically but with a maximum in the morning and a minimum in the afternoon (Jiang et al., 2011). Considering this phase opposition with the evolution of Helene, an internal forcing did not appear to be the cause of the intensifications of Helene.

\subsection{Crucial phasing of Helene with the Rossby wave train}

Here, the description of the RWT is compared between HiRes and LowRes before and after the third intensification. At 1200 UTC 24 September $(t+60$, Figure 9, top $)$, remnants of the filament $\mathrm{F}_{2}$ south of Helene were similar in HiRes and LowRes. Both runs also showed a similar underestimation of the downstream ridge with respect to the ECMWF analysis. A crucial difference between HiRes and LowRes was propagating from upstream: the elongating filament $\mathrm{F}_{3}$ was shifted eastward in LowRes. This difference originated in the breaking of $\mathrm{T}_{\text {up }}$ over central USA during the first hours of simulation. The resulting shift of $\mathrm{F}_{3}$, combined with a delay in the track of Helene in LowRes, modified the relative position of the two structures.

The phasing between Helene and $\mathrm{F}_{3}$ strongly impacted their mutual interaction and differences between HiRes and LowRes became evident after the third intensification at 1200 UTC 25 September $(t+84$, Figure 9, bottom $)$. The filament $\mathrm{F}_{3}$ was separating from the upper-level trough and elongating southwards after an intense wrap-up around Helene. It was closer in LowRes than in HiRes prior to the interaction and so wrapped around Helene more. The resulting elongation of $\mathrm{F}_{3}$ was close to the analysis in HiRes, whereas it was underestimated in LowRes.

This difference was responsible for the bifurcation in the track of Helene, as discussed below. The more pronounced wrap-up of $\mathrm{F}_{3}$ in LowRes than in HiRes also induced a stronger reintensification of Helene. The difference in the relative position of Helene and $\mathrm{F}_{3}$ is of the same order as the $250 \mathrm{~km}$ displacement of Bart (1999) used by Klein et al. (2002) for sensitivity runs. An equivalent $2.5^{\circ}$ eastward displacement was sufficient for Jangmi (2008) to reintensify instead of decaying (Grams, 2011). These results show the high sensitivity to relatively small errors in phasing-much smaller than the $5^{\circ}$ increment in the idealised simulations of Ritchie and Elsberry (2007).

Figure 9 also shows another interaction with the RWT upstream of Helene. The surface low $\mathrm{L}_{\mathrm{US}}$ contributed to the building of a ridge over the Labrador Sea, then occluded off Newfoundland at 1200 UTC 25 September $(t+84)$. In a similar way, a cyclogenesis upstream of Hanna (2008) diabatically modified the RWT during the ET of Hanna (Grams et al., 2011). When compared to the analysis, the deepening of $\mathrm{L}_{U S}$ and the resulting ridging were underestimated in HiRes and overestimated in LowRes. This difference also originated from earlier errors in the phasing of $\mathrm{L}_{\mathrm{US}}$ with the RWT over the northeastern USA. 
(a) ECMWF

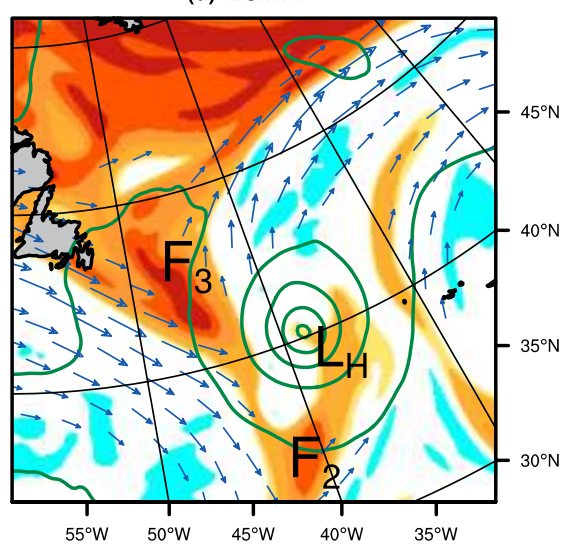

(d) ECMWF (b) HiRes

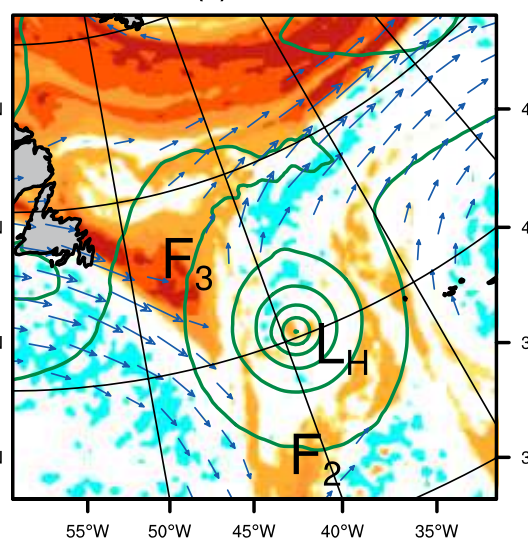

(e) HiRes (c) LowRes

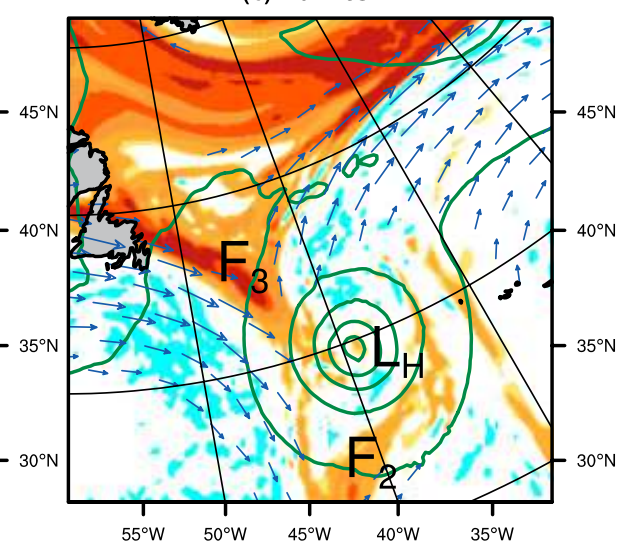

(f) LowRes

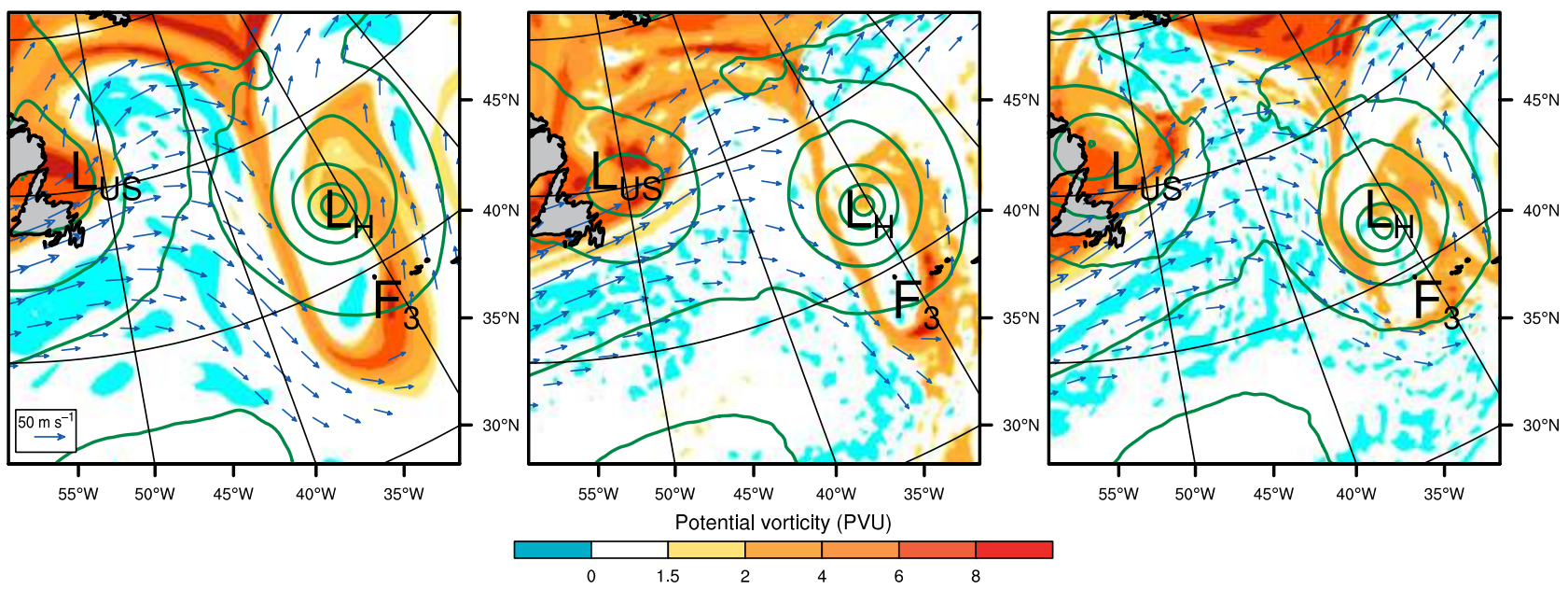

Figure 9. $250 \mathrm{hPa}$ potential vorticity (shading, PVU), $250 \mathrm{hPa}$ wind (vectors above $30 \mathrm{~m} \mathrm{~s}^{-1}$ ) and MSLP (contours every $10 \mathrm{hPa}$ ) at (a-c) $1200 \mathrm{UTC} 24$ September $(t+60)$ and at $(\mathrm{d}-\mathrm{f}) 1200$ UTC 25 September $2006(t+84)$. All fields are interpolated on the same $24 \mathrm{~km}$ grid. Labels mark the position of Helene $\left(\mathrm{L}_{\mathrm{H}}\right)$, the US low $\left(\mathrm{L}_{\mathrm{US}}\right)$ and two PV filaments $\left(\mathrm{F}_{2}\right.$ and $\left.\mathrm{F}_{3}\right)$. This figure is available in colour online at wileyonlinelibrary.com/journal/qj

However, the resulting change in the downstream ridge impacted on RWT too late to influence the fate of Helene.

\subsection{Bifurcation of the track of Helene}

The steering of Helene was investigated at 1200 UTC 25 September $(t+84)$ in order to understand the difference between HiRes and LowRes. The cyclonic circulation of Helene was isolated using the Helmholtz partitioning method (described in section 3.2) and was subtracted from the total wind field (Figure 10(a)). The remaining flow represented the environment that steered Helene and conditioned its track (Figure 10(b)). The wind field was considered over the whole free troposphere in order to encompass both high- and low-level circulations. Such a definition of the evolving steering flow was validated against the track of Helene during the whole ET.

As in the ECMWF analysis, Helene was steered northeastwards by the ambient flow in HiRes (Figure 10(c)). Accordingly, its track was tangential to the environmental stream function. In contrast, Helene was steered southeastwards in LowRes (Figure 10(d)), with a track again explained by the tangent environmental stream function. This initially small difference in the meridional flow then increased dramatically from 0000 UTC 26 September $(t+96)$ and Helene curved northwards in HiRes and southwards in LowRes.
Remnants of the filament $\mathrm{F}_{3}$ are easily recognizable in the environmental vorticity field (Figure 10 (b, c, d)). The extraction of Helene marks a clear hole and emphasizes its immediate proximity to the PV filament. An objective discrimination of the two structures was not possible because of the intrusion of environmental vorticity into Helene. However, an increase or decrease of the attribution radius by $50 \mathrm{~km}$ did not significantly change the present diagnosis. In contrast, a larger attribution radius containing $\mathrm{F}_{3}$ led to a similar flow in LowRes and HiRes. This flow was zonal in the vicinity of Helene and could explain neither the northeastward track in HiRes nor the southwestward track in LowRes. The bifurcation of tracks was therefore caused by remnants of $\mathrm{F}_{3}$ and not by any dynamical feature present outside this subdomain.

This diagnosis shows how the track of Helene was determined by the environmental steering at the end of the ET, itself sensitive to the earlier phasing of Helene with $\mathrm{F}_{3}$. This high sensitivity was also noted in sensitivity runs starting from different initialization times. It is reminiscent of the bifurcation in the track of a TC when it approaches a saddle point of the environmental stream function, as discussed by Scheck et al. (2011) in barotropic simulations. Defining a trough-relative stream function, Grams (2011) showed the existence of such a saddle point during the ET of Jangmi (2008). 
(a) ECMWF

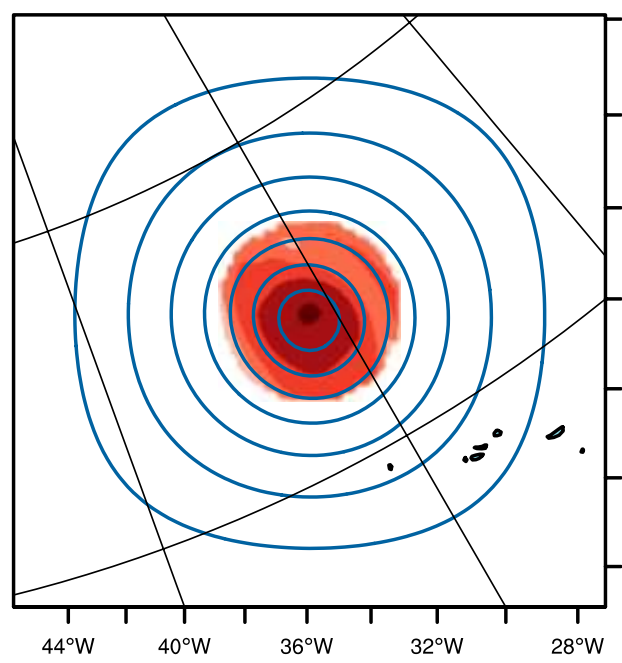

(c) HiRes (b) ECMWF

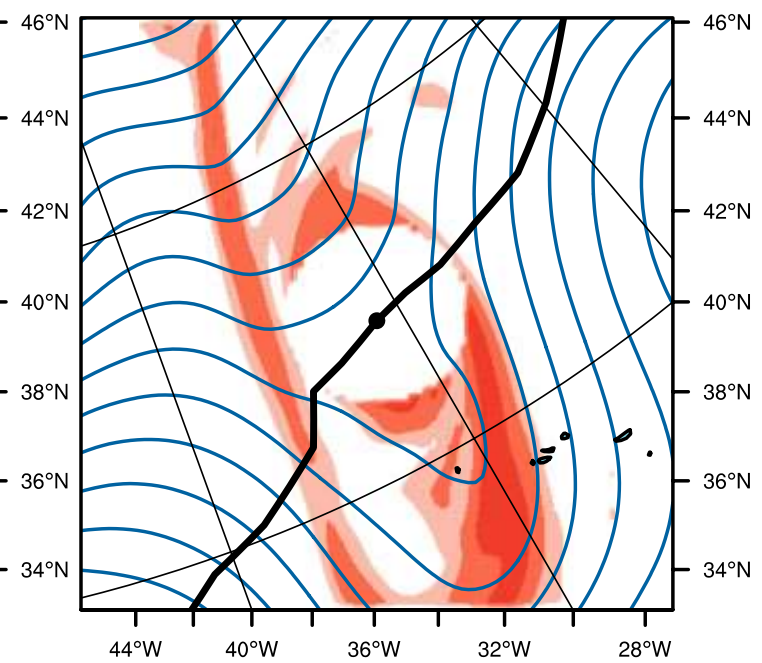

(d) LowRes

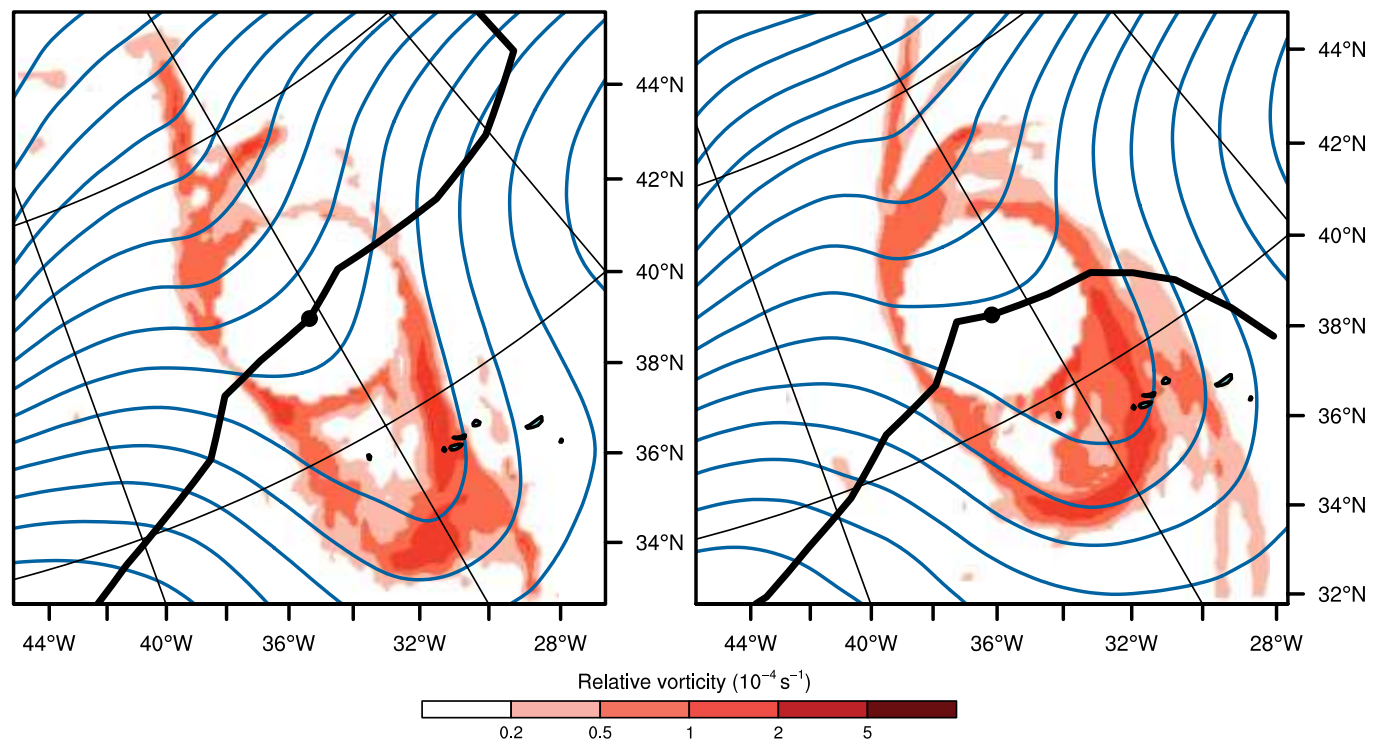

Figure 10. Vertically averaged vorticity between 950 and $250 \mathrm{hPa}$ every $50 \mathrm{hPa}$ (shading, $10^{-5} \mathrm{~s}^{-1}$, positive values only) and corresponding stream function (contours every $2 \times 10^{6} \mathrm{~m}^{2} \mathrm{~s}^{-1}$ ) at 1200 UTC 25 September $(t+84)$. Top panels: circulation of (a) Helene and (b) the environment in the ECMWF analysis. Bottom panels: circulation of the environment in (c) HiRes and (d) LowRes. Location (dot) and track (thick line) of the MSLP minimum of Helene. All fields are interpolated on the same $24 \mathrm{~km}$ grid. This figure is available in colour online at wileyonlinelibrary.com/journal/qj

\section{Impact of Helene on the Rossby wave train and downstream consequences}

The influence of the RWT has been shown on both the intensity and the track of Helene. We now investigate the feedback of Helene on RWT. The coupling of the outflow of Helene with the downstream jet and the wrap-up of PV filaments by the cyclonic circulation of Helene was suggested in Figure $6(\mathrm{~d}-\mathrm{f})$. They were tested in sensitivity runs with a vanishing or absent TC. In the short term, these runs emphasized local modifications of the RWT induced by Helene. In the long term, they revealed the downstream propagation of the local modifications.

\subsection{Local modifications from diabatic heating}

The impact of the outflow of Helene on the upper-level circulation was assessed with short-term sensitivity runs at $24 \mathrm{~km}$ grid spacing (hereafter NoHeat), in which the diabatic heating was switched off. These tests were run for
$12 \mathrm{~h}$, to examine the change in cyclone dynamics and its close environment only and to avoid any impact on the large scale. They were initialized from output fields of LowRes at 1200 UTC $22(t+12), 23(t+36)$ and $24(t+60)$ September, during each intensification of Helene. In all three sensitivity runs, a quick filling of $10 \mathrm{hPa}$ in $12 \mathrm{~h}$ occurred and Helene lost its warm core as expected without diabatic heating.

Figure 11 compares LowRes with the sensitivity run NoHeat for the second intensification at 0000 UTC 24 September. In LowRes, the strong diabatic heating produced a dipole of potential vorticity, with high values at low level that maintained the PV tower and negative values at high level. The strong ascent further produced a strong divergence at high level, which along with the low-PV air prevented the upstream trough from approaching Helene. The strong cyclone outflow at high level coupled with the downstream jet streak, which strengthened above $90 \mathrm{~m} \mathrm{~s}^{-1}$. Low-PV air was also advected by the jet and contributed to the downstream ridge building. These effects of the diabatic 
(a) LowRes

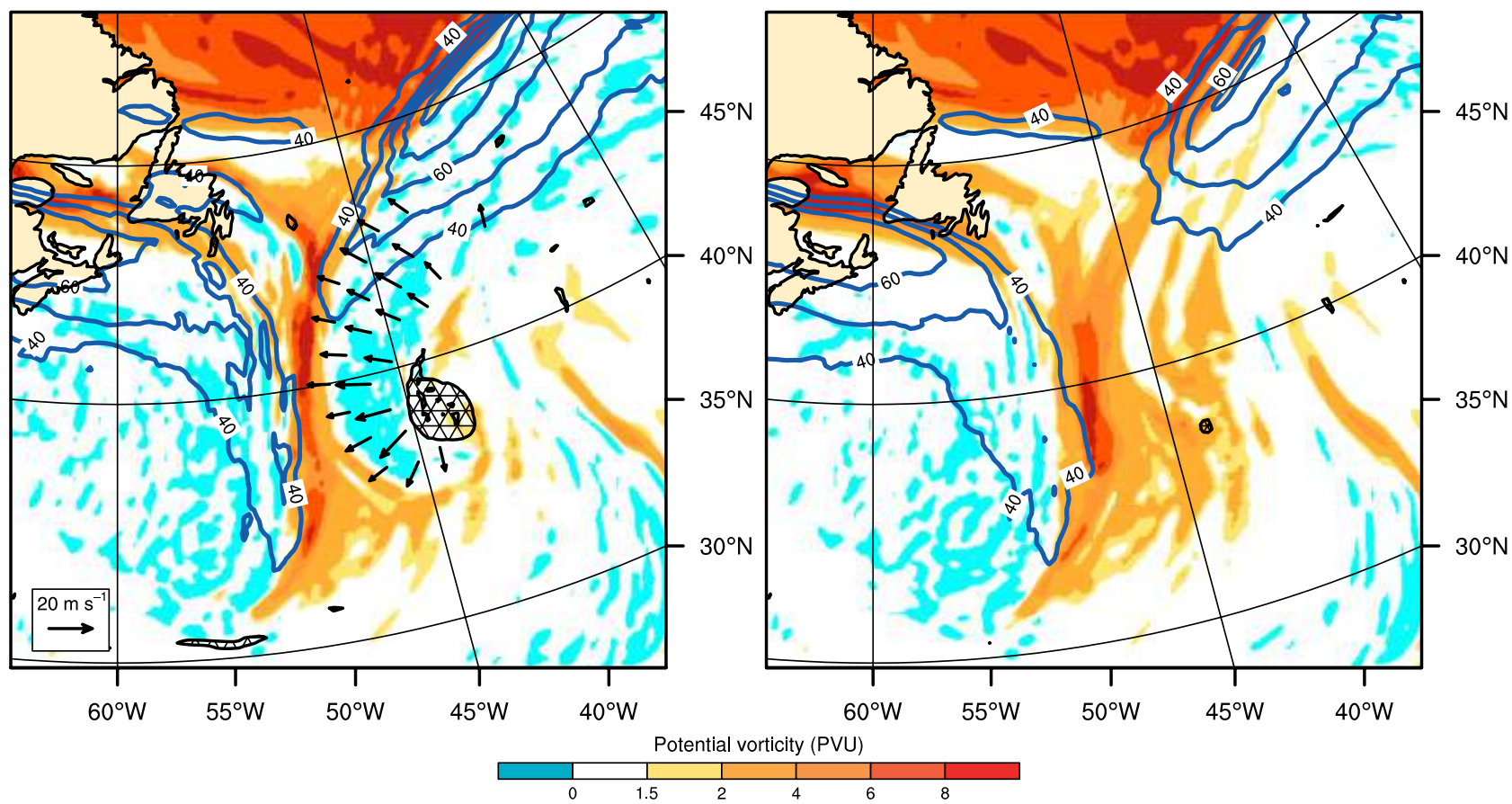

Figure 11. Meso-NH (a) LowRes and (b) NoHeat runs at 0000 UTC 24 September $2006(t+48$ and $t+12$, respectively). 250 hPa potential vorticity (shading, PVU), $250 \mathrm{hPa}$ divergent wind (vectors above $10 \mathrm{~m} \mathrm{~s}^{-1}$ ), $250 \mathrm{hPa}$ wind speed (contours above $40 \mathrm{~m} \mathrm{~s}^{-1}$ each $10 \mathrm{~m} \mathrm{~s}^{-1}$ ) and $850 \mathrm{hPa}$ potential vorticity (hatched above $3 \mathrm{PVU}$ ). This figure is available in colour online at wileyonlinelibrary.com/journal/qj

heating match the conceptual model of Agusti-Panareda et al. (2004).

Without diabatic heating, the low-level potential vorticity dramatically vanished (Figure 11(b)). At upper levels, the lack of low-PV air and divergent wind in the vicinity of Helene allowed the upstream trough to superpose on the cyclone remnants without wrapping around them. In the absence of the cyclone contribution, the downstream jet streak weakened to a maximum wind speed of $80 \mathrm{~m} \mathrm{~s}^{-1}$ and did not advect low-PV air towards the ridge, which was displaced southwards. During the two other intensifications, the sensitivity runs showed similar effects in the absence of diabatic heating.

The diabatic and dynamical forcings were previously compared for the strong ascent along a warm front (Figure 7). The sensitivity runs performed here confirm the role of diabatic heating in maintaining the strong activity of Helene during its ET. The resulting outflow had a double impact on the RWT: it delayed the eastward advection of PV filaments upstream of Helene and it contributed to the building of a ridge downstream. The latter effect propagated further downstream, in particular over Europe, as discussed in the next section. A similar diabatic impact of the outflow of Irene (1999) on an upstream trough delayed the intensification of Irene as an extratropical cyclone (Agusti-Panareda et al., 2004). In the same way, the eastward motion of an RWT was delayed by the cyclone outflow in idealized (Riemer et al., 2008) and real-case studies (Grams, 2011).

\subsection{Downstream development on the Mediterranean}

Another test was performed to evaluate the total impact of Helene on RWT during its ET and its consequences on the downstream development of the medicane $\mathrm{L}_{\mathrm{M}}$. A run (hereafter NoHel) was started from a modified ECMWF analysis at 0000 UTC 22 September, where the wind, temperature and humidity anomalies related to Helene were filtered out following the method explained in section 3.2. The NoHel run described how RWT would have evolved if the ET of Helene had not occurred. Apart from its initial conditions, NoHel was performed with the same lateral boundaries, resolution and physical parametrizations as LowRes.

A weak cyclone remained after the filtering with an MSLP minimum around $1010 \mathrm{hPa}$. It had lost its warm core and associated PV tower and its remnants quickly dissipated during the first hours of simulation. Precipitation was found along the frontal zone and was still produced in the surrounding tropical sector but without any organized convection. The upper-level trough, which interacted with Helene in LowRes, broke cyclonically in NoHel (Figure 12(a)). It favoured surface cyclogenesis that led to a well-defined low (hereafter $\mathrm{L}_{\mathrm{NoHel}}$ ) from 15 UTC 23 September $(t+39)$ with a central pressure of 989 $\mathrm{hPa}$. This low $\mathrm{L}_{\mathrm{NoHel}}$ quickly deepened to $974 \mathrm{hPa}$ in 24 $\mathrm{h}$ before occluding and filling. The RWT then evolved in a different fashion without Helene. At 0000 UTC 26 September $2006(t+96)$, the upper-level trough on the central Atlantic was still present in NoHel, whereas it had vanished in LowRes (Figure 12(b)). Differences propagated downstream and increased over central Europe, where a ridge in NoHel replaced an elongating trough in LowRes. This impact on the synoptic situation for Europe emphasizes the importance of the representation of Helene during its ET for the predictability downstream.

The quick dissipation of the hurricane remnants in NoHel clearly shows that the presence of Helene was essential to its own reintensification. The role of Helene 
(a) 0000 UTC 24 Sep

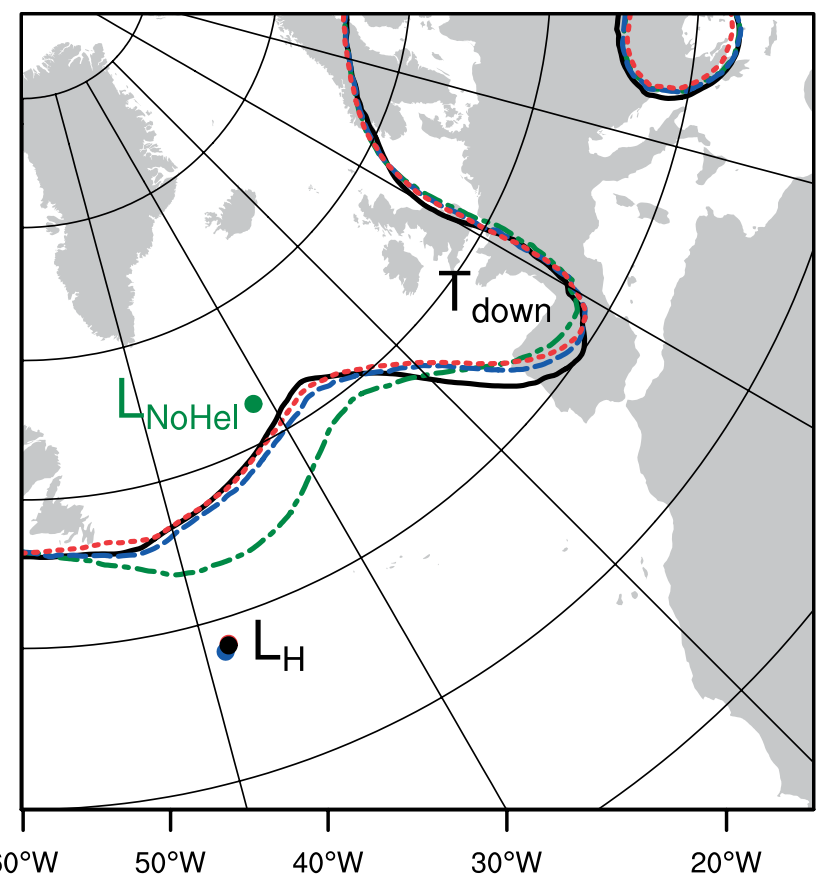

(b) 0000 UTC 26 Sep

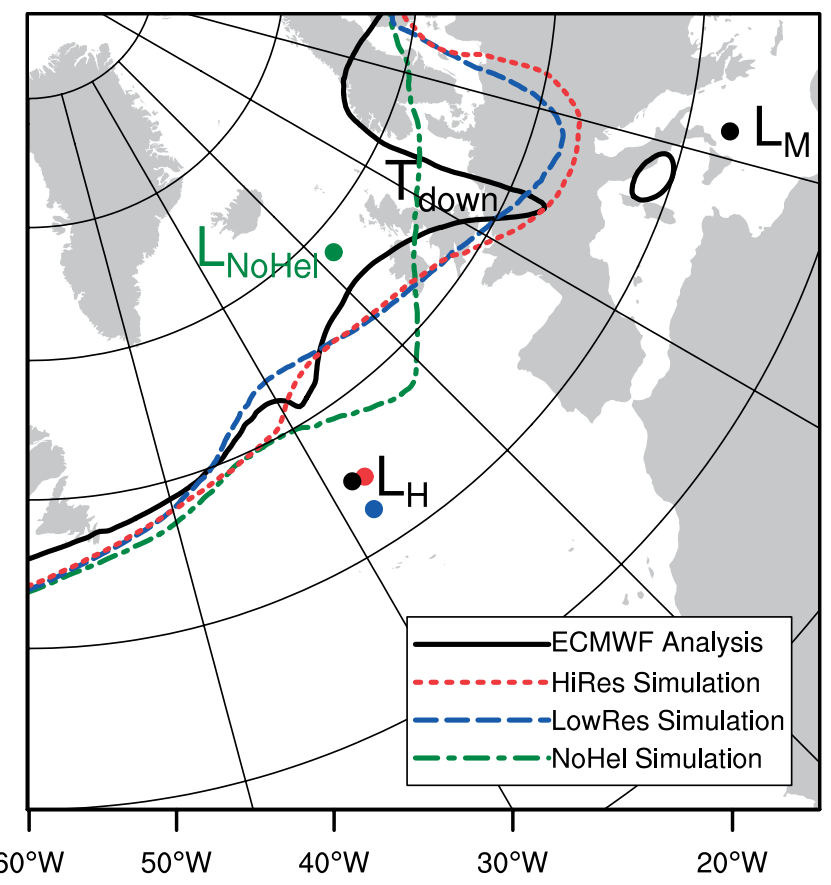

Figure 12. $250 \mathrm{hPa}$ geopotential height (contour at $10500 \mathrm{~m}$ ) at (a) $0000 \mathrm{UTC} 24$ September $(t+48)$ and (b) $0000 \mathrm{UTC} 26 \mathrm{September} 2006(t+96)$, in the ECMWF analysis and Meso-NH HiRes, LowRes and NoHel runs. Labels mark the position of Helene ( $\left.\mathrm{L}_{\mathrm{H}}\right)$, the low that developed without Helene $\left(\mathrm{L}_{\mathrm{NoH}}\right)$, the Medicane $\left(\mathrm{L}_{\mathrm{M}}\right)$ and the upper-level trough downstream $\left(\mathrm{T}_{\text {down }}\right)$. This figure is available in colour online at wileyonlinelibrary.com/journal/qj

is comparable to that of Danielle (1998) during its tropicalmode reintensification (McTaggart-Cowan et al., 2004). The filtering of Helene further helps in understanding the origin of the three intensifications during the ET. Three PV filaments also formed every day on the central North Atlantic in NoHel as in HiRes and LowRes. This suggests that the origin of the quasi-diurnal intensifications of Helene lies in the external forcing due to the dynamics of the RWT. However, the impact of Helene on the PV filaments was again essential to the reintensification. In the absence of the cyclonic circulation of Helene, the two first PV filaments broke anticyclonically (unlike $\mathrm{F}_{1}$ and $F_{2}$ ), whereas the third one broke cyclonically (like $F_{3}$ ) and triggered surface cyclogenesis. According to the classification of Agusti-Panareda et al. (2005), the role of Helene was crucial to its reintensification in the development associated with $F_{1}$ and $F_{2}$, while it was significant but not crucial in the development associated with $\mathrm{F}_{3}$.

Figure 12 also provides an estimation of the error propagation with RWT in HiRes and LowRes. At 0000 UTC 24 September $(t+48)$, both runs slightly underestimated the building of a ridge downstream of Helene and the deepening of a trough over Europe. The specificity of the ridge being too zonal might be linked to the lack of model precipitation along the extended front northeast of Helene (Figure $6(\mathrm{a}-\mathrm{c}))$. Figure 12 further suggests that the error propagated downstream and was responsible for the toozonal trough over Europe. At 0000 UTC 26 September 2006 $(t+96)$, the error had amplified and both runs missed the formation of a cut-off low over southern Italy originating from the elongating trough. In consequence, two ingredients were missing in both runs for the development of the tropical-like storm $\mathrm{L}_{\mathrm{M}}$ over the Mediterranean. First, the wind was too weak to form a surface low on the lee side of the Atlas Mountains (Moscatello et al., 2008). Second, the upper-level trough did not break cyclonically over
Italy to create favourable conditions for rapid cyclogenesis (Chaboureau et al., 2012). Some differences were detected between the two runs but remained smaller than the discrepancy with the ECMWF analysis; the increase of resolution in HiRes did not improve the forecast over the Mediterranean. The bifurcation of tracks occurred after the third reintensification of Helene only, too late to diabatically modify the RWT.

\subsection{Error propagation with the Rossby wave train}

A Hovmöller plot, showing the temporal evolution of the upper-level geopotential, is used here to summarize the interactions that occurred during the ET of Helene (Figure 13(a)). It allows RWTs to be tracked, though their identification is not unique and depends on the type of Hovmöller plot (Glatt et al., 2011). Helene $\left(\mathrm{L}_{H}\right)$ became phase-locked on 22 September near $60^{\circ} \mathrm{W}$ with RWT, which existed prior to its arrival. The maximal wave amplitude quickly propagated downstream, revealing the group speed of RWT, while it decreased until 1200 UTC 24 September along the track of Helene. The two first PV filaments $\mathrm{F}_{1}$ and $\mathrm{F}_{2}$ formed from RWT and interacted with Helene. Downstream, the upper-level trough $\mathrm{T}_{\text {down }}$ from RWT elongated into a PV streamer, inducing the rapid cyclogenesis of $\mathrm{L}_{\mathrm{M}}$ over the Mediterranean on 26 September.

Upstream of Helene, the upper-level trough $\mathrm{T}_{\text {up }}$ broke on 22 September over the central USA. The resulting upperlevel anomaly induced the cyclogenesis of $\mathrm{L}_{\mathrm{US}}$ late on 23 September over the northeastern USA near $90^{\circ} \mathrm{W}$. The anomaly propagated further downstream and contributed to the formation of $\mathrm{F}_{3}$, which interacted with Helene late on 24 September over the Atlantic Ocean near $30^{\circ} \mathrm{W}$. The RWT had a zonal group speed of about $35^{\circ}$ longitude per day, as estimated from the amplitude maxima. 
(a) ECMWF

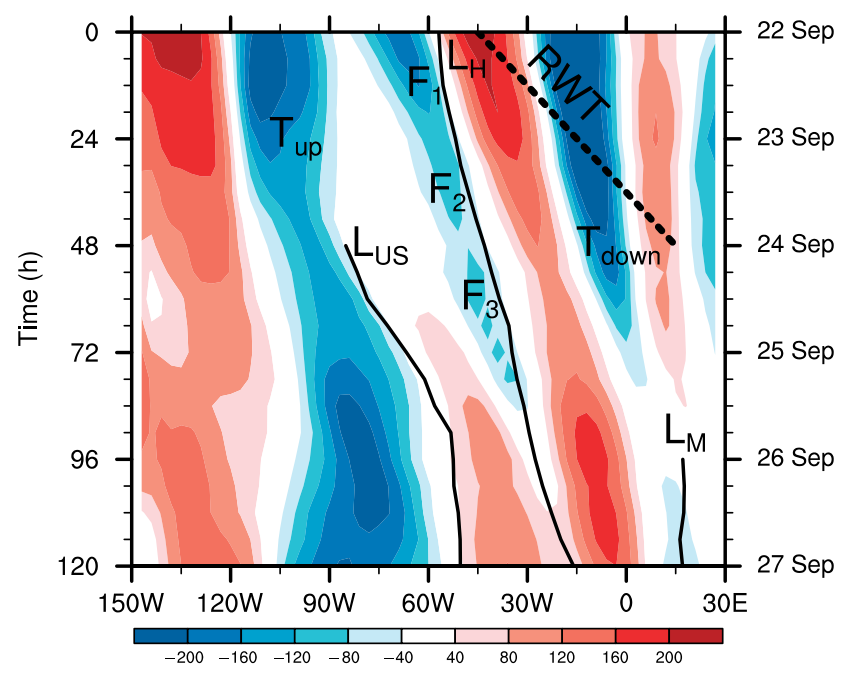

(b) LowRes - ECMWF

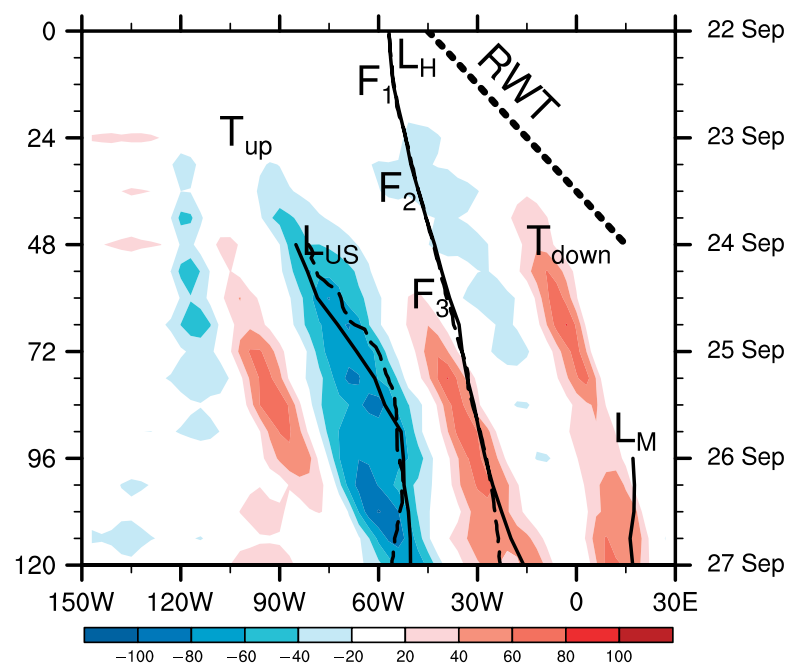

Figure 13. Hovmöller plots of the geopotential height anomaly at $250 \mathrm{hPa}$ (shading, $\mathrm{m}$ ) from $0000 \mathrm{UTC} 22 \mathrm{September} 2006$ averaged between $30^{\circ} \mathrm{N}$ and $60^{\circ} \mathrm{N}$. (a) ECMWF analysis and (b) difference between Meso-NH LowRes run and ECMWF analysis. Longitude of the MSLP minimum of Helene $\left(\mathrm{L}_{\mathrm{H}}\right)$, the US low ( $\left.\mathrm{L}_{\mathrm{US}}\right)$ and the Medicane $\left(\mathrm{L}_{\mathrm{M}}\right)$ are shown from the ECMWF analysis (thin solid lines) and the Meso-NH LowRes run (thin dashed lines). Thick dashed lines denote the wave speed of the Rossby wave train RWT. Additional labels mark the position of the PV filaments $\mathrm{F}_{1}, \mathrm{~F}_{2}, \mathrm{~F}_{3}$ and the upper-level troughs upstream $\mathrm{T}_{\mathrm{up}}$ and downstream $\mathrm{T}_{\text {down }}$. This figure is available in colour online at wileyonlinelibrary.com/journal/qj

The RWT encourages the model errors to quickly propagate downstream, as shown with another Hovmöller plot of the differences in the upper-level geopotential between LowRes and the ECMWF analysis (Figure 13(b)). A similar propagation of model errors was found in HiRes (not shown). A negative bias of geopotential was present along the track of Helene $\mathrm{L}_{\mathrm{H}}$ during and after its interaction with $\mathrm{F}_{2}$. It corresponded to the underestimation of the downstream ridge building in LowRes. This bias propagated downstream with the group speed of RWT and led to the underestimation of the elongation of $\mathrm{T}_{\text {down }}$. The bias resulted in the absence of the development of $\mathrm{L}_{\mathrm{M}}$ over the Mediterranean in LowRes.

Another negative bias of geopotential took its origin in the breaking of $\mathrm{T}_{\text {up }}$ over the central USA. It propagated downstream with the same speed as RWT, though it did not belong to the RWT. The bias first led to an eastward shift of the cyclogenesis of $\mathrm{L}_{\mathrm{US}}$ over the northeastern USA from 0000 UTC 24 September $(t+48)$, then impacted the interaction of $\mathrm{F}_{3}$ with Helene from 1800 UTC 24 September $(t+66)$. This last modification resulted in the southward steering of Helene after 0600 UTC 25 September $(t+78)$, which grew into the bifurcation of its track in LowRes. A positive bias appeared at 0000 UTC 25 September $(t+72)$ near $90^{\circ} \mathrm{W}$ and also propagated downstream with the same speed as RWT. It affected the track of $\mathrm{L}_{\mathrm{US}}$ but did not reach Helene during the simulation.

These examples show how quickly model errors propagate and amplify with the RWTs. A high sensitivity in the track of Helene made it strongly dependent on the accuracy of a Rossby wave breaking over the central USA 2 days earlier and the downstream propagation of uncertainties from the outflow of Helene impacted the mid-range predictability in Europe.

\section{Conclusion}

The ET of Helene over the North Atlantic was investigated with a focus on the role of an RWT. Numerical experiments were performed in regional and cloud-resolving modes with grid spacings of 24 and $4 \mathrm{~km}$, respectively. The simulation domain covered a semi-hemisphere to encompass the full RWT that interacted with Helene. The Rossby wave train played an important role in the track and intensity of Helene and in a Mediterranean cyclogenesis downstream. The role of Helene was also essential to its own reintensification.

The ET began on 22 September 2006 and lasted for 3 days before Helene filled up as an extratropical cyclone. The overlap of the transformation and reintensification stages differed from the conceptual model of Klein et al. (2000). Helene further maintained its deep warm core during the whole ET. Other cases of ET developed a warm core like Earl and Danielle (1998), during a baroclinic and tropical reintensification, respectively (McTaggart-Cowan et al., 2003). However, these cases first developed a cold core before their reintensification, unlike Helene.

During ET, Helene reintensified three times in a quasidiurnal oscillation. Every time, a PV filament elongated from the RWT and wrapped around Helene prior to its deepening. This suggests that the RWT forced the three successive intensifications of Helene. The elongation of the three PV filaments in a numerical experiment where Helene was filtered out confirmed that the three intensifications took their origin in the dynamics of the RWT. The possibility of an internal diurnal cycle of Helene was dismissed. Still, Helene was essential to its own reintensification. A weak remnant cyclone dissipated quickly when the circulation and moisture anomaly of Helene were filtered out. Helene further contributed to its own reintensification through its interaction with the PV filaments. By comparing simulations with and without Helene, its role was classified as crucial in forcing the cyclonic wrap-up of the first two PV filaments, according to the terminology of Agusti-Panareda et al. (2005). The role of Helene in the third wrap-up was significant but not crucial.

Diabatic effects were essential to the activity of Helene and had a large impact on the ET. A strong diabatic response to a weak dynamical forcing at low and upper levels resulted in a mix of deep convection in the core and slantwise convection over a warm front to the northwest of Helene. 
In the mid troposphere, the diabatic heating maintained the warm core and the cyclonic circulation of Helene. At upper levels, it produced low-PV air and enhanced the divergent outflow, modifying the RWT locally. The broadening of the PV filaments was prevented upstream, while an accelerated jet streak advected low-PV air downstream and contributed to the building of a ridge. This impact of diabatic effects confirms the PV-based conceptual model of AgustiPanareda et al. (2004) for the ET of Irene (1999) and matches the interpretation of Grams et al. (2011) for the ET of Hanna (2008).

We expected an increase of the model resolution to enhance the description of the strong diabatic effects. Surprisingly, the precipitation and cloud fields were similar in the regional and cloud-resolving runs, both in good agreement with satellite observations. This showed the skill of the model in representing Helene during its ET. Furthermore, it revealed that the diabatic heating was forced by mesoscale ascents and not by a convective instability. The model resolution had a strong impact on Helene through the dynamics of the RWT. It was found that a difference in their phasing of Helene with the third PV filament was crucial at the end of ET. The existence of such a bifurcation point in the steering of a TC was recently revealed by Scheck et al. (2011) and Grams (2011) in the early phases of ET. Here, the third PV filament was too close to Helene in the regional run, leading to a stronger intensification and an incorrect southeastward steering of Helene. Only the cloud-resolving run succeeded in modelling the correct northeastward track of Helene. This improvement in the track of Helene originated from differences due to the increased resolution, not only around Helene but also upstream over North America.

The RWT quickly propagated model errors with a group speed of about $35^{\circ}$ longitude per day. Early uncertainties in the breaking of an upper-level trough over the central USA were responsible for the bifurcation of tracks between the runs. In addition, uncertainties in the outflow of Helene were propagated downstream and impacted the elongation of an upper-level trough over Europe. In consequence, neither the regional nor the cloud-resolving run succeeded in modelling the development of a tropical-like storm over the Mediterranean. Such a reduced predictability downstream of Helene was typical of an ET event (Anwender et al., 2008; Harr et al., 2008). This downstream impact was further demonstrated by the filtering of Helene at the beginning of its ET, which dramatically changed the synoptic conditions over Europe after the ET.

The reduced predictability over Europe and the Mediterranean was partly due to a misrepresentation of the interaction of Helene with the RWT. In particular, the lack of precipitation observed along the warm front northeast of Helene might explain the underestimation of the downstream ridge building, which resulted in the absence of the medicane. Torn (2010) recently showed that the frontal precipitation was the main dynamical mechanism for the downstream ridge building during the ET of Tokage (2004). Here, the discrepancy in the location and intensity of precipitation along the warm front suggests additional sensitivity runs for future work. The impact of changes in the microphysical scheme and other sources of model uncertainties on the ET could be assessed. Errors from the initial conditions provided by the ECMWF analysis cannot be rejected either. This other source of uncertainties could also be tested by using perturbed initial conditions such as those built for ensemble forecasts. This would advance our understanding of the high sensitivity of Helene to its phasing with the RWT.

Furthermore, it would be interesting to apply the present methodology to other cases of ET. The three successive deepenings and the bifurcation of tracks seen for Helene make this case unusual and complex. The role of the RWT could be assessed with simpler cases, as a single interaction of a TC with a RWT generally occurs during an ET event. In addition, an increase of the model resolution could have a direct impact on the TC itself if diabatic effects had smaller-scale characteristics than in the present case.

\section{Acknowledgements}

The authors thank Juan Escobar for his development and support in running Meso-NH on massively parallel computers, and Jean-Pierre Cammas for the use of the alternative balance omega inversion code and discussions about its interpretation. The first author warmly thanks Sarah Jones and her team for their welcome and helpful discussions during a research stay at the Karlsruhe Institute of Technology. Constructive and detailed comments from two anonymous reviewers helped to improve the manuscript. This study was sponsored by the French Ministry of Research through project ANR-VMC2007 'Forecast and projection in climate scenario of Mediterranean intense events: Uncertainties and Propagation on environment' (MedUP) and by the Institut National des Sciences de l'Univers through the EPIGONE project. The first author was supported by a CNRS and Météo-France $\mathrm{PhD}$ grant. Computer resources were allocated by GENCI (project 90569). AMSU data were obtained through the French Mixed Service Unit ICARE. Globally merged IR Brightness Temperature Data were downloaded from the NASA Mirador website.

\section{References}

Agusti-Panareda A, Thorncroft C, Craig G, Gray S. 2004. The extratropical transition of hurricane Irene (1999): a potential vorticity perspective. Q. J. R. Meteorol. Soc. 130: 1047-1074.

Agusti-Panareda A, Gray S, Craig G, Thorncroft C. 2005. The extratropical transition of tropical cyclone Lili (1996) and its crucial contribution to a moderate extratropical development. Mon. Weather Rev. 133: 1562-1573.

Anwender D, Harr PA, Jones SC. 2008. Predictability associated with the downstream impacts of the extratropical transition of tropical cyclones: case studies. Mon. Weather Rev. 136: 3226-3247.

Bechtold P, Bazile E, Guichard F, Mascart P, Richard E. 2001. A mass flux convection scheme for regional and global models. Q. J. R. Meteorol. Soc. 127: 869-886.

Belamari S. 2005. Report on uncertainty estimates of an optimal bulk formulation for surface turbulent fluxes. Technical report, MERSEA IP Deliverable, D.4.1.2, 29.

Buehler SA, John VO. 2005. A simple method to relate microwave radiances to upper tropospheric humidity. J. Geophys. Res. 110: D02110, DOI: 10.1029/2004JD005111.

Chaboureau JP, Bechtold P. 2005. Statistical representation of clouds in a regional model and the impact on the diurnal cycle of convection during Tropical Convection, Cirrus and Nitrogen Oxides (TROCCINOX). J. Geophys. Res. 110: D17103, DOI: 10.1029/2004JD005645.

Chaboureau JP, Söhne N, Pinty JP, Meirold-Mautner I, Defer E, Prigent C, Pardo JR, Mech M, Crewell S. 2008. A midlatitude cloud database validated with satellite observations. J. Appl. Meteorol. Climatol. 47: 1337-1353.

Chaboureau JP, Pantillon F, Lambert D, Richard E, Claud C. 2012. Tropical transition of a Mediterranean storm by jet crossing. Q. J. R. Meteorol. Soc. 138: 596-611. 
Colella P, Woodward P. 1984. The piecewise parabolic method (PPM) for gas-dynamical simulations. J. Comput. Phys. 54: 174-201.

Cuxart J, Bougeault P, Redelsperger JL. 2000. A turbulence scheme allowing for mesoscale and large-eddy simulations. Q. J. R. Meteorol. Soc. 126: $1-30$.

Davis CA, Jones SC, Riemer M. 2008. Hurricane vortex dynamics during Atlantic extratropical transition. J. Atmos. Sci. 65: 714-736.

Davis C, Wang W, Dudhia J, Torn R. 2010. Does increased horizontal resolution improve hurricane wind forecasts? Weather Forecast. 25: 1826-1841.

Durran DR. 1989. Improving the anelastic approximation. J. Atmos. Sci. 46: $1453-1461$

Franklin JL, Brown DP. 2008. Atlantic hurricane season of 2006. Mon. Weather Rev. 136: 1174-1200.

Glatt I, Doernbrack A, Jones S, Keller J, Martius O, Mueller A, Peters DHW, Wirth V. 2011. Utility of Hovmoller diagrams to diagnose Rossby wave trains. Tellus 63: 991-1006.

Grams C. 2011. Quantification of the downstream impact of extratropical transition for typhoon Jangmi and other case studies. $\mathrm{PhD}$ thesis, Karlsruhe Institute of Technology. http://www.imktro.kit.edu/english/4328_5346.php.

Grams CM, Wernli H, Böttcher M, Čampa J, Corsmeier U, Jones SC, Keller JH, Lenz CJ, Wiegand L. 2011. The key role of diabatic processes in modifying the upper-tropospheric wave guide: a North Atlantic case-study. Q. J. R. Meteorol. Soc. 137: 2174-2193.

Harr PA, Dea JM. 2009. Downstream development associated with the extratropical transition of tropical cyclones over the western North Pacific. Mon. Weather Rev. 137: 1295-1319.

Harr P, Elsberry R, Hogan T. 2000. Extratropical transition of tropical cyclones over the western North Pacific. Part II. The impact of midlatitude circulation characteristics. Mon. Weather Rev. 128: 2634-2653.

Harr PA, Anwender D, Jones SC. 2008. Predictability associated with the downstream impacts of the extratropical transition of tropical cyclones: methodology and a case study of Typhoon Nabi (2005). Mon. Weather Rev. 136: 3205-3225.

Hart RE. 2003. A cyclone phase space derived from thermal wind and thermal asymmetry. Mon. Weather Rev. 131: 585-616.

Jiang H, Liu C, Zipser EJ. 2011. A TRMM-based tropical cyclone cloud and precipitation feature database. J. Appl. Meteorol. Climatol. 50(6): $1255-1274$.

Jones SC, Harr PA, Abraham J, Bosart LF, Bowyer PJ, Evans JL, Hanley DE, Hanstrum BN, Hart RE, Lalaurette F, Sinclair MR, Smith RK, Thorncroft C. 2003. The extratropical transition of tropical cyclones: forecast challenges, current understanding, and future directions. Weather Forecast. 18: 1052-1092.

Keller JH, Jones SC, Evans JL, Harr PA. 2011. Characteristics of the TIGGE multimodel ensemble prediction system in representing forecast variability associated with extratropical transition. Geophys. Res. Lett. 38: L12802, DOI: 10.1029/2011GL047275.

Klein P, Harr P, Elsberry R. 2000. Extratropical transition of western North Pacific tropical cyclones: an overview and conceptual model of the transformation stage. Weather Forecast. 15: 373-396.

Klein P, Harr P, Elsberry R. 2002. Extratropical transition of western North Pacific tropical cyclones: midlatitude and tropical cyclone contributions to reintensification. Mon. Weather Rev. 130: 2240-2259.

Kurihara Y, Bender M, Ross R. 1993. An initialization scheme of hurricane models by vortex specification. Mon. Weather Rev. 121: 2030-2045.
Lafore JP, Stein J, Asencio N, Bougeault P, Ducrocq V, Duron I, Fischer C, Héreil P, Mascart P, Masson V, Pinty JP, Redelsperger JL, Richard E, Vilà-Guerau de Arellano J. 1998. The Meso-NH Atmospheric Simulation System. Part I. Adiabatic formulation and control simulations. Scientific objectives and experimental design. Ann. Geophys. 16: 90-109.

Lang STK, Jones SC, Leutbecher M, Peng MS, Reynolds CA. 2012. Sensitivity, structure, and dynamics of singular vectors associated with hurricane Helene (2006). J. Atmos. Sci. 69: 675-694.

Laviola S, Levizzani V. 2011. The 183-WSL fast rain rate retrieval algorithm. Part I. Retrieval design. Atmos. Res. 99: 443-461.

Lynch P. 1989. Partitioning the wind in a limited domain. Mon. Weather Rev. 117: 1492-1500.

Mallet I, Cammas JP, Mascart P, Bechtold P. 1999. Effects of cloud diabatic heating on the early development of the FASTEX IOP17 cyclone. Q. J. R. Meteorol. Soc. 125: 3439-3467.

McTaggart-Cowan R, Gyakum J, Yau M. 2001. Sensitivity testing of extratropical transitions using potential vorticity inversions to modify initial conditions: Hurricane Earl case study. Mon. Weather Rev. 129: $1617-1636$.

McTaggart-Cowan R, Gyakum J, Yau M. 2003. The influence of the downstream state on extratropical transition: Hurricane Earl (1998) case study. Mon. Weather Rev. 131: 1910-1929.

McTaggart-Cowan R, Gyakum J, Yau M. 2004. The impact of tropical remnants on extratropical cyclogenesis: case study of hurricanes Danielle and Earl (1998). Mon. Weather Rev. 132: 1933-1951.

Moscatello A, Miglietta MM, Rotunno R. 2008. Numerical analysis of a Mediterranean 'hurricane' over southeastern Italy. Mon. Weather Rev. 136: 4373-4397.

Nuissier O, Rogers RF, Roux F. 2005. A numerical simulation of hurricane Bret on 22-23 August 1999 initialized with airborne Doppler radar and dropsonde data. Q. J. R. Meteorol. Soc. 131 155-194.

Pantillon F, Mascart P, Chaboureau JP, Lac C, Escobar J, Duron J. 2011. Seamless MESO-NH modeling over very large grids. C. R. Mecanique 339: $136-140$

Pergaud J, Masson V, Malardel S, Couvreux F. 2009. A parameterization of dry thermals and shallow cumuli for mesoscale numerical weather prediction. Bound.-Lay. Meteorol. 132: 83-106.

Pinty JP, Jabouille P. 1998. A mixed-phase cloud parameterization for use in a mesoscale non-hydrostatic model: simulations of a squall line and of orographic precipitations. In Conference on Cloud Physics, Everett, WA. American Meteorological Society; 217-220.

Riemer M, Jones SC. 2010. Downstream impact of tropical cyclones on a developing baroclinic wave in idealized scenarios of extratropical transition. Q. J. R. Meteorol. Soc. 136: 617-637.

Riemer M, Jones SC, Davis CA. 2008. The impact of extratropical transition on the downstream flow: an idealized modelling study with a straight jet. Q. J. R. Meteorol. Soc. 134: 69-91.

Ritchie EA, Elsberry RL. 2007. Simulations of the extratropical transition of tropical cyclones: phasing between the upper-level trough and tropical cyclones. Mon. Weather Rev. 135: 862-876.

Scheck L, Jones SC, Juckes M. 2011. The resonant interaction of a tropical cyclone and a tropopause front in a barotropic model. Part II. Frontal waves. J. Atmos. Sci. 68(3): 420-429.

Schwendike J, Jones SC. 2010. Convection in an African Easterly Wave over West Africa and the eastern Atlantic: a model case study of Helene (2006). Q. J. R. Meteorol. Soc. 136(SI): 364-396.

Torn RD. 2010. Diagnosis of the downstream ridging associated with extratropical transition using short-term ensemble forecasts. J. Atmos. Sci. 67: 817-833. 